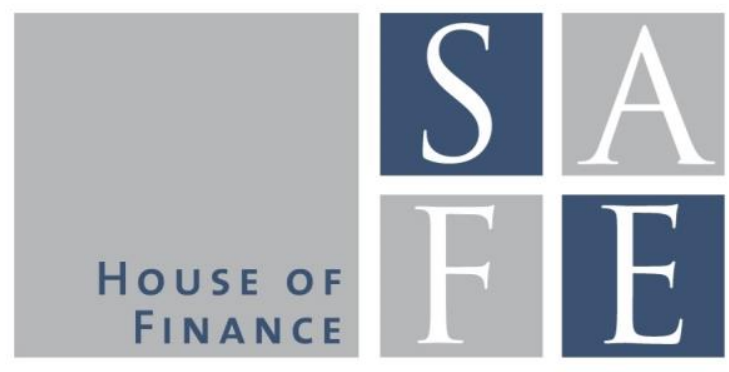

Working PAPER SERIES

Michael Donadelli - Renatas Kizys - Max Riedel

\title{
Globally Dangerous Diseases: Bad News for Main Street, Good News for Wall Street?
}

SAFE Working Paper No. 158

SAFE I Sustainable Architecture for Finance in Europe A cooperation of the Center for Financial Studies and Goethe University Frankfurt 


\section{Non-Technical Summary}

Mood and anxiety in the stock market - coined as investor sentiment - are documented in asset pricing literature to have a significant impact on returns. The variety of mood variables studied in the past ranges from weather conditions and international sporting events to negative newspaper articles on aviation disasters and wars. Also, interpersonal communication, leading to 'social mood', was observed to translate into emotions such as optimism, pessimism, happiness, or anxiety. A general finding is that fear leads to negative asset returns while positive emotions increase investors' willingness to take risks.

Differently from the existing works, this study examines whether investor mood, driven by World Health Organization (WHO) alerts and media news on globally dangerous diseases, is priced in pharmaceutical companies' stocks in the United States. We focus on four major diseases that were regarded as a Public Health Emergency of International Concern (PHEIC) by the WHO. These include the outbreak of severe acute respiratory syndrome (SARS) in 2003, Influenza A (H1N1) in 2009, and Polio and Ebola in 2014. Specifically, our main contribution consists of employing a novel mood variable (disease-related news or DRN), based on WHO alerts and media news on a globally dangerous disease, to examine the effect of investor sentiment on pharmaceutical stock prices.

We concentrate on irrational investors who buy and sell pharmaceutical companies' stocks guided by beliefs as opposed to rational expectations. We argue that rational trading should not occur because of two reasons. First, in the wake of DRNs, uncertainty surrounding distant cash flows of vaccine developers may be too high. Second, resources available for smaller pharmaceutical companies may be too limited to engage in large-scale R\&D. As a result, pharmaceutical stock prices should not respond to DRNs.

To address our research questions, we construct four daily pharmaceutical investment portfolios covering the years 2003 to 2014. The empirical strategy draws upon two commonly used - eventstudy and regression-based - methodologies to evaluate the investor sentiment effect on stock prices of pharmaceutical firms following a DRN.

Our findings show that DRNs have a positive and significant sentiment effect among investors (on Wall Street). The effect is stronger (weaker) for small (large) companies that are less (more) likely to engage in the development of new vaccines in the wake of DRNs. A potential negative mood (on Main Street) - induced by disease-related fear - does not alter the positive sentiment effect. These results give rise to profitable trading strategies leading to sizable outperformances over the market portfolio. Importantly, returns on DRN-based trading strategies are economically and statistically greater than returns on randomly drawn strategies.

Overall, our study shows that optimism and pessimism - induced by DRNs - can significantly influence portfolio investment decisions in the pharmaceutical industry. Our findings are of importance and practical usefulness for institutional and individual investors, portfolio managers, financial analysts and pharmaceutical firms alike. 


\title{
Globally Dangerous Diseases: Bad News for Main Street, Good News for Wall Street?
}

\author{
Michael DONADELLI, Renatas KIZYS and Max RIEDEL *
}

\begin{abstract}
This paper examines whether investor mood, driven by World Health Organization (WHO) alerts and media news on globally dangerous diseases, is priced in pharmaceutical companies' stocks in the United States. We concentrate on irrational investors who buy and sell pharmaceutical companies' stocks guided by beliefs as opposed to rational expectations. We argue that disease-related news (DRNs) should not trigger rational trading. We find that DRNs have a positive and significant sentiment effect among investors (on Wall Street). The effect is stronger (weaker) for small (large) companies, who are less (more) likely to engage in the development of new vaccines in the wake of DRNs. A potential negative mood (on Main Street) - induced by diseaserelated fear - does not alter the positive sentiment effect. Our findings give rise to profitable trading strategies leading to significantly positive performances. Overall, this unparalleled research shows that large events of devastating nature to the economy can be considered as good news to some groups of interest, such as stock market traders.
\end{abstract}

Keywords: WHO alerts, investor sentiment, pharmaceutical industry, trading strategies

JEL Codes: G11, G14, I11

*Michael Donadelli (e-mail: michael.donadelli@gmail.com, phone: +49 69798 33882) and Max Riedel (e-mail: riedel@safe.uni-frankfurt.de, phone: +4969798 30069) are both at the Research Center SAFE. Renatas Kizys (e-mail: renatas.kizys@port.ac.uk, phone: +44 2392 844635) is affiliated with the University of Portsmouth. We would like to thank Michela Altieri, Giuliano Curatola, Alessandro Gioffré, Longarela Iñaki Rodríguez, Marie Lalanne, Robin Lumsdaine, Christian Schlag and Ansgar Wohlschlegel along with seminar participants at the 2015 Frankfurt-Muenster Asset Pricing Workshop, the 11th BMRC-DEMS Conference on Macro and Financial Economics/Econometrics, 2015 PBS Research Conference, the XXIII Spanish Finance Forum, Graduate School of Social Sciences (Hiroshima University), the 2015 SFM Conference, ISM University of Management and Economics (Vilnius), Nagasaki University, South Western University of Finance and Economics (Chengdu), University of Malaga. We gratefully acknowledge research support from the Research Center SAFE, funded by the State of Hessen initiative for research LOEWE. Some of the work on this paper was completed while Kizys was visiting the Research Center SAFE and while Donadelli and Riedel were visiting Portsmouth Business School. All remaining errors are our own. 


\section{Introduction}

A relatively large number of studies shows that sentiment may drive agents' investment decisions (see, among others, De Long et al., 1990; Cen and Liyan-Yang, 2013; Kaplanski and Levy, 2015). In this respect, the behavioral finance literature provides solid evidence supporting the existence of a significant relation between stock returns and investor sentiment. ${ }^{1}$ Investor sentiment is typically defined as a belief about future cash flows and investment risks that is not justified by the facts at hand (see Baker and Wurgler (2007), pp. 129). Certain events may create either a positive or a negative sentiment that strongly affects investors' investment decisions and, thus, the corresponding stock market prices.

Early studies observe, for example, that sunshine, which is well known to be a driver of peoples' mood, tends to comove positively with daily stock returns (see Saunders, 1993; Hirshleifer and Shumway, 2003). Yuan et al. (2006) find that lunar phases may affect stock market returns. More recent studies find that international sporting games - and in particular soccer games - heavily affect investors' sentiment, and in turn, stock market returns (see Edmans et al., 2007; Kaplanski and Levy, 2010a). Kaplanski and Levy (2010b) show that major aviation disasters tend to generate a negative sentiment within two days after the event. Horváth and Huizinga (2015) examine the impact of the announcement on the creation of the European Financial Stability Facility on bank share prices.

Key in this research is the possibility - hitherto unaccounted for by existing literature - that large events of devastating nature to the economy and society can be regarded as good news to some groups of interest, such as stock market investors. Differently from the existing works, we rely on globally dangerous diseases (i.e., SARS, Influenza A(H1N1), Polio, Ebola), which are perceived by the general public (Main Street) as large negative developments, but can generate sector-specific positive investor sentiment (Wall Street). Specifically, our main contribution consists of employing a novel mood variable (hereinafter disease-related news or DRNs), based on World Health Organization's alerts and media news related to globally dangerous diseases, to examine the effect of investor sentiment on

\footnotetext{
${ }^{1}$ See, among others, Saunders (1993); Hirshleifer and Shumway (2003); Kamstra et al. (2003); Loughran and Schultz (2004); Cao and Wei (2005); Baker and Wurgler (2006); Edmans et al. (2007); Kaplanski and Levy (2010a,b); Curatola et al. (2016)
} 
pharmaceutical stock prices. Our principal hypothesis here is that fear of globally dangerous diseases will be negatively associated with investor pessimism, whereas DRNs will positively affect investment in pharmaceutical stocks. This hypothesis builds on the argument that while globally dangerous diseases spread fear and generate negative sentiment - investors unrealistically anticipate an increase in cash flows of pharmaceutical companies due to selling new medicines aimed at fighting the new pandemic disease.

Thus, investor sentiment about the performance of pharmaceutical companies may be one key element that drives financial investment decisions. This notwithstanding, there is a dearth of research into pharmaceutical companies' stock market performance (see Himmelmann and Schiereck, 2012; Theodossiou and Theodossiou, 2014).

To the best of our knowledge, the relation between pharmaceutical stock returns and investor sentiment - driven by DRNs - has not been investigated in the literature, with the exception of Huberman and Regev (2001). Huberman and Regev (2001) use a case study to investigate the effect of investor enthusiasm to a major breakthrough in cancer research. Interestingly, the stock price of EntreMed, a bio-pharmaceutical company, responded stronger to the breakthrough five months later, when it was reported in the popular press, than when it was originally announced in Nature. Nevertheless, their research neither (i) generalizes to the whole pharmaceutical industry, nor (ii) studies investor sentiment effects on stock prices and returns, nor (iii) designs global disease-news-induced trading strategies.

The main contribution of this study is to evaluate the balance between two contrasting effects of outbreaks of globally dangerous diseases. On the one hand, we recognize the possibility that pandemic diseases spread fear among the general public and stock market investors, which triggers a negative (fear-induced) sentiment in pharmaceutical stock prices. On the other hand, an outbreak of a pandemic disease is expected to have a positive sectorspecific sentiment effect on pharmaceutical stock prices. Methodologically, accounting for the two competing (negative and positive) effects manifests in a unique framework that alleviates the possibility of spurious correlations. In more detail, this study addresses the following questions, hitherto unedited in the context of pharmaceutical stock market. First, does investors' fear gauge, which is provoked by DRNs, lead to a decrease in pharmaceutical stock market returns? Second, does an outbreak of a globally dangerous disease trigger a 
positive sector-specific investor sentiment effect on pharmaceutical stock prices? Third, does investor sentiment (optimism or pessimism) about future performance of pharmaceutical companies persist over time? Fourth, do stock prices of large pharmaceutical stocks respond to DRNs differently than stock prices of small pharmaceutical stocks?

To address these issues, we use stock prices of 102 pharmaceutical firms listed in the United States to construct four different investment portfolios. In addition, as robustness check, we consider the S\&P500 Information Technology stock index. Our empirical strategy draws upon two commonly used - event-study and regression-based - methodologies to evaluate the investor sentiment effect on stock prices of pharmaceutical firms following a DRN.

We identify a significantly positive and persistent investor sentiment - following DRNs - in stock returns of pharmaceutical companies. This may be generated by positive beliefs about R\&D investments in the aftermath of disease outbreaks. Notice also that the persistence of investor sentiment may be reflected in information salience (Palomino et al., 2009). Furthermore, we construct a fear gauge index by employing the stock market volatility index VIX as a proxy for investor fear. The index always exerts a negative and significant effect on returns of pharmaceutical companies' stocks. We find that sentiment tends to exert a stronger effect on small firms than on large firms. This finding is along the lines of Qiu and Welch (2004) who observe that, under certain conditions, small firm returns become a proxy for investor sentiment (see also Edmans et al., 2007; Baker and Wurgler, 2006). Importantly, our results are supported by a battery of robustness checks.

Overall, our findings give rise to profitable trading strategies where an investor takes a long-position in a portfolio of pharmaceutical stocks and a short one in the stock market volatility index (i.e., VIX). We stress that these strategies lead to a significant positive performance.

The remainder of this study is organized as follows. In Section 2, we provide the background and motivation to the study. In Section 3, we describe our mood variable DRN and report descriptive statistics. In Section 4, we outline the methodology and formulate our main hypotheses. In Section 5, we discuss the estimation results. In Section 6, we design hypothetical trading strategies. Finally, in Section 7, we provide some concluding remarks 
and we also shed light on the practical usefulness of our results.

\section{Motivation and Background}

\subsection{Investor Sentiment and Media Coverage: The Case of Pan- demic Diseases}

Mood and anxiety in the stock market - coined as investor sentiment - are documented in asset pricing literature to have a significant impact on stock market returns. ${ }^{2}$ Mehra and Sah (2002) relate in a theoretical framework the effect of feelings on investors' decision making in financial markets. Nofsinger (2005) finds that interpersonal communication, leading to "social mood", translates into emotions such as optimism, pessimism, happiness, or anxiety. A general finding is that fear leads to negative asset returns while positive emotions increase investors' willingness to take risks.

In this study, we hypothesize that increased media coverage of globally dangerous diseases has a positive and relatively persistent effect on pharmaceutical companies. Despite the overall negative sentiment in the population due to fear of being infected, public and political demand for containing a global epidemic disease can lead to additional income channels for pharmaceutical companies. Typical reactions to an infectious illness include higher R\&D investment (partially subsidized by the government), vaccine mass orders, or general increase in demand for preventive measures (e.g., medicine, disinfection agents, surgical masks). We focus on four major diseases that were regarded as a Public Health Emergency of International Concern (PHEIC) by the WHO. The outbreak of severe acute respiratory syndrome (SARS) in 2003, Influenza A(H1N1) in 2009, and Polio and Ebola in 2014 were all more or less intensively covered by media.

The role of mass media in communication of risks has been subject to intense debate. It is argued that low-probability, high-consequence events, such as health risks associated with outbreaks of rare diseases, are overemphasized in media-generated news waves. This

\footnotetext{
${ }^{2}$ In the literature, a variety of mood variables was considered. For instance, weather conditions (Saunders, 1993; Hirshleifer and Shumway, 2003), hours of daylight in fall and winter (Kamstra et al., 2003), international soccer results (Edmans et al., 2007; Kaplanski and Levy, 2010a; Curatola et al., 2016), or negative newspaper articles (Tetlock, 2007).
} 
unbalanced reporting leads to a disjunction between actual and population's perceived risk (see Vasterman et al., 2005; Mairal, 2011; Young et al., 2013). ${ }^{3}$ Public overreaction and panic can also lead to adverse economic effects. In particular, sectors such as tourism or retail sales fall due to individuals' preventive measures, such as reduction in traveling to the affected geographical areas or avoidance of public places. ${ }^{4}$

In the spirit of Kaplanski and Levy (2010b), we search for media articles related to globally dangerous diseases in order to $(i)$ gain better understanding of the scale and timing of the information salience of such diseases and $(i i)$ to evaluate the importance of the information salience as a potential source of investor sentiment in the pharmaceutical industry. Figure 1 illustrates the normalized number of media news informing the general public about the outbreak and acceleration for the aforementioned pandemic diseases. It is evident from Figure 1 that the frequency of the relevant news notably increases on the announcement day $(t=0)$, that is, when the official WHO PHEIC statement is made. The news coverage intensifies and attains maximum on the third day after the official WHO PHEIC announcement. In addition, the absolute number of news remains above the average up to six days after the announcement. This is not surprising since PHEIC statements are followed by other official/institutional news, which will be used to build our event-day mood variable in the next section. Specifically, in two out of four cases an event (i.e., DRNs) was taking place on any of the seven days following a PHEIC announcement. These observations provide support for the existence of a relative strong relationship between official news and media coverage and therefore between DRNs and investor sentiment. Moreover, they suggest that such sentiment effect lasts for several days supporting the persistent sentiment hypothesis that will be formulated in Section 4 .

\footnotetext{
${ }^{3}$ For instance, a representative survey conducted by Blendon et al. (2004) indicates that $69 \%$ of respondents living in Ontario, $57 \%$ in Canada excluding Ontario and $32 \%$ in the United States were concerned about contracting SARS. Whereas, educative and informative communication to the public in Singapore resulted in a much lower overall anxiety level. Quah and Hin-Peng (2004) report that only $14 \%$ of respondents viewed SARS as a personal risk in May 2003.

${ }^{4}$ In case of SARS, Hanna and Yiping (2004) estimate the total cost at about 0.5\% of GDP in China, while Keogh-Brown and Smith (2008) assess the global economic impact between USD 30 and 100bn. Using a general equilibrium model for the UK, Smith et al. (2009) estimate costs related to Influenza A(H1N1) between $0.5 \%$ and $1.0 \%$ of UK's GDP. However, the total economic burden is difficult to quantify since both direct health care costs as well as indirect costs of work absenteeism and loss of productivity have to be taken into account.
} 
Figure 1: Media Coverage around PheiC alerts on Globally Dangerous Diseases

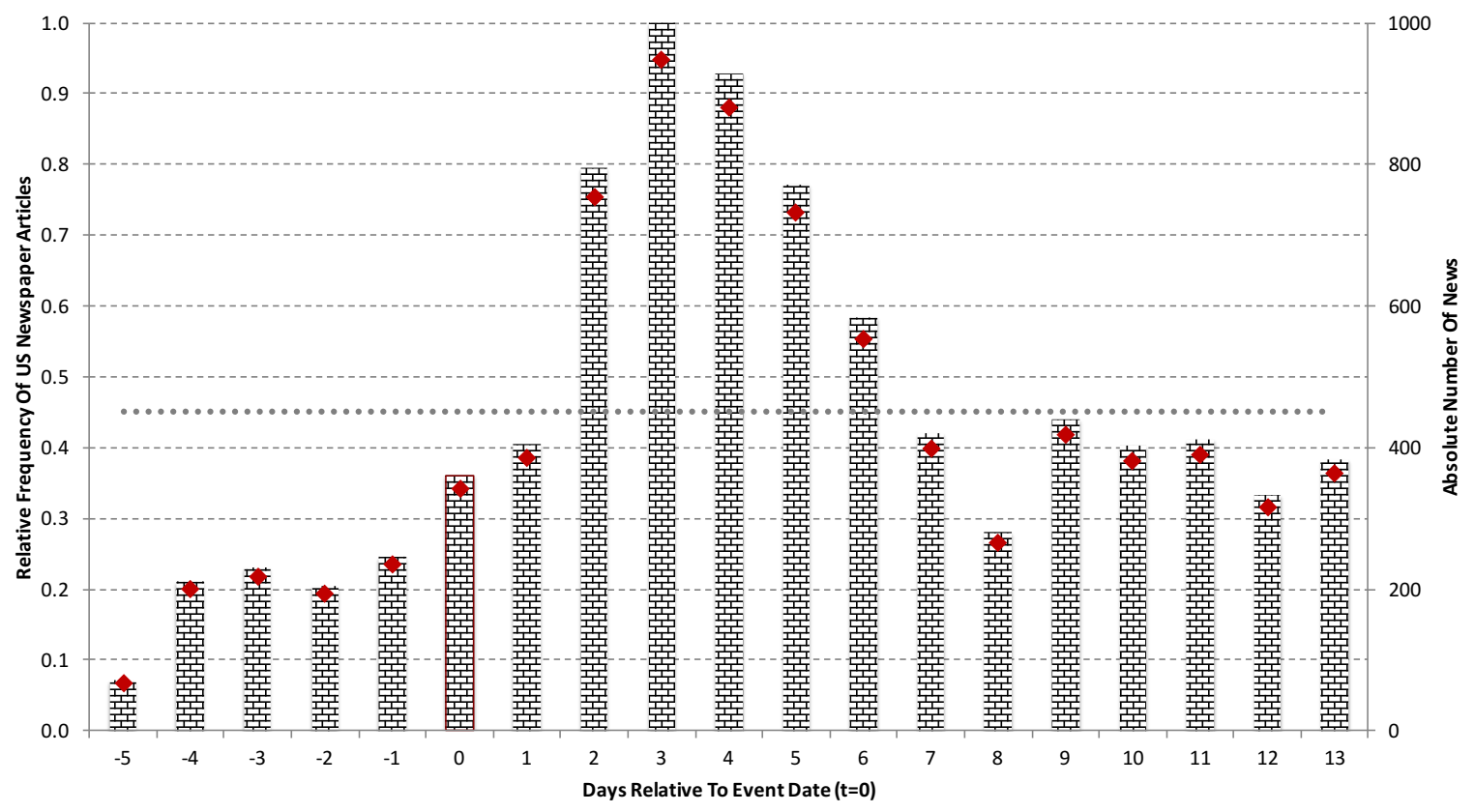

Notes: This figure depicts the normalized number of distinct, disease-related newspaper articles published in the United States around the event days. The event dates $(t=0)$ are considered to be the official PHEIC statements. The number of articles relies on all four disease announcements and is normalized relative to the its peak value over the 19 days period. The dotted line represents the average relative value across the 19 days period. Red points illustrate the absolute number of disease-related newspaper articles. Data are obtained using the LexisNexis database for global news and business information.

\subsection{The Pharmaceutical Industry}

The pharmaceutical industry is at the heart of the US economy. Although public and private spending on pharmaceuticals in the US collectively contributed just over 2\% (around USD $1,000)$ to the country's GDP per capita in 2011 (OECD, 2013), ${ }^{5}$ this share was the largest among the OECD countries. In 2009, the overall US health care expenditure accounted for $18 \%$ of the country's GDP, but it is estimated to contribute $37 \%$ in $2050 .{ }^{6}$ Furthermore, biopharmaceutical companies in the US account for the largest share of all US companies' R\&D expenditure, which represents nearly $20 \%$ of all domestic R\&D (PhRMA, 2015). ${ }^{7}$ This is one of the fastest growing industries. Indeed, both revenues and R\&D spending by the US biopharmaceutical industry tripled from 1996 to 2008 (Lazonick and Tulum, 2011). Fur-

\footnotetext{
${ }^{5}$ Source: OECD Health Statistics (2013).

${ }^{6}$ Source: The Statistics Portal (Statista), 2015 (available at www.statista.com/statistics/215163/ushealth-expenditure-as-percentage-of-gdp-forecast).

${ }^{7}$ Source: The Pharmaceutical Research and Manufacturers of America (PhRMA) (available at www.phrma.org/economic-impact).
} 
ther, Offit (2005) documents an increase in market concentration of vaccine producers in the US over past decades. Specifically, there are currently only four FDA-approved US-based publicly-traded vaccine producers and distributors. ${ }^{8}$ The reasons for companies undertaking or quitting vaccine production are multi-fold. On the one hand, research, development, testing, and manufacturing of vaccines are costly; on the other hand, the market for selling vaccines is smaller than the market for pharmaceutical drugs, to name just few reasons. However, high entry barriers for the development of a new vaccine bears potential for monopoly. Additionally, there is no manufacturing of generic vaccines, as vaccine production is substantially more complicated and technologically advanced than drug production. A generic drug is defined by the WHO as "a pharmaceutical product, usually intended to be interchangeable with an innovator product, that is manufactured without a licence from the innovator company and marketed after the expiry date of the patent or other exclusive rights" ${ }^{9}$. The result is an increase in vaccine shortages, especially for flu vaccines (Hinman et al., 2006). The emergence of a globally dangerous disease can thus be regarded as a potentially new market for vaccine producers along with subsidized R\&D. Therefore, it is surprising that research focusing on the effects of investors' sentiments on the stock prices of pharmaceutical companies has been underwhelming.

\subsection{The US Stock Market and Investor Attention to Pharma- Stocks}

This empirical study focuses on the US stock market. There are two main reasons to select the US stock market for this study: (1) it is one of the most closely followed markets in the world and, as such, very efficient with respect to new information inflow as well as one of the most liquid ones (see, among others, Kaplanski and Levy, 2010a); (2) the US stock market is one of the leading stock markets in the world and accounts for about $40 \%$ of the global market (Hou et al., 2011). ${ }^{10}$ Our study is further motivated by a growing role of pharmaceutical

\footnotetext{
${ }^{8}$ FDA's "Complete List of Vaccines Licensed for Immunization and Distribution in the US" includes Emergent Biosolutions, Johnson \& Johnson, Merck and Pfizer (available at www.fda.gov/BiologicsBloodVaccines/Vaccines/ApprovedProducts/ucm093833.htm).

${ }^{9}$ www.who.int/trade/glossary/story034/en/

${ }^{10}$ Notice that the average stocks traded (as \% of GDP) in the US over the last decade is above $200 \%$ (Source: World Development Indicators).
} 
companies' stocks within the industry of financial services in the US. Perceptive Life Sciences Offsh Fund LTD (USD 859M), Traxis Sivik Global Healthcare Offshore (USD 44M), and Visium Balanced Offshore Fund CL2 (USD 3,697M) are examples of the sector-specific equity funds investing exclusively in bio-pharmaceutical stocks. ${ }^{11}$ There is also a large number of funds with significant exposures to stocks of (main) individual pharmaceutical companies. Indeed, Table 1 indicates that, as of second quarter of 2014, institutional investors hold significant positions in largest pharmaceutical firms' stocks, including Pfizer, Johnson \& Johnson, Merck \& Company, AstraZeneca, Amgen and Gilead Sciences Inc.

Table 1: Institutional Investors' Positions in (Main) Pharmaceutical Stocks

\begin{tabular}{ll}
\hline Pharmaceutical Company & Fund (\% of pharma stocks held) \\
\hline Pfizer & Jana Partners (0.05\%); Fairfax Financial Holdings (0.48\%); Orbimed Advisors \\
& $(1.42 \%) ;$ Eton Park Capital Management (1.53\%), Boyar Asset Management (3.94\%); \\
& York Capital Management Global Advisors (1.35\%); Farallon Capital Management \\
& $(0.43 \%)$, Muhlenkamp and Co (0.21\%) \\
& Berkshire Hathaway (0.03\%); Fairfax Financial Holdings (0.61\%); Perry Corp \\
Johnson \& Johnson & $(0.99 \%) ;$ Orbimed Advisors (0.59\%); Boyar Asset Management (2.14\%); \\
& Chou Associates Management (0.14\%); \\
Glaxo & Fairfax Financial Holdings (0.05\%); Orbimed Advisors (1.72\%); Healthcor Manage- \\
Merck \& Company & ment (1.69\%); Vertex One Asset Management (0.67\%); Sarissa Capital (7.87\%); \\
Abbott Laboratories & Southeastern Asset Management (27, 2.98\%); \\
AstraZeneca & Chou Associates Management (0.28\%); Third Point (0.91\%), Corvex Management \\
& $(1.09 \%) ;$ Duquesne Family Office (1.11\%); Highfields Capital Management (0.76\%); \\
& York Capital Management Global Advisors (1.20\%) \\
Amgen & Third Point (0.65\%); Orbimed Advisors (3.12\%); Pennant Capital Management \\
& $(0.50 \%) ;$ Highline Capital Management (7.06\%); Sarissa Capital (1.81\%); \\
Lilly Eli \& Co & Highfields Capital Management (2.13\%); \\
Bristol Myers Squibb Co & Orbimed Advisors (4.09\%); Boyar Asset Management (2.12\%); Muhlenkamp and Co \\
& $(1.82 \%)$ \\
Gilead Sciences Inc. & Baker Bros. Advisors (0.26\%); Palo Alto Investors (0.95\%); Orbimed Advisors \\
& $(3.34 \%) ;$ Pennant Capital Management (3.07\%); Argonaut Capital Management \\
& $(1.25 \%) ;$ Healthcor Management (2.69\%); Parnassus Investments (2.44\%); Muh- \\
lenkamp and Co (2.12\%) & \\
Vertex Pharmaceuticals Inc & Orbimed Advisors (0.59\%); Healthcor Management (3.88\%); \\
Novo Nordisk & Markel Corp (1.42\%) \\
\hline Source: Form 13F (SEC) - Reports Filed by Institutional Investment Managers
\end{tabular}

\section{Data}

\subsection{Official Announcements of Globally Dangerous Diseases}

The data cover the entire history of global diseases that were considered as PHEICs by the WHO - a 12-year period, from March 2003 to December 2014. The global diseases period

\footnotetext{
${ }^{11}$ Source: HSBC Hedge Weekly n. 28 - Investment Fund Performance Review, July 2014.
} 
incorporates 146 DRNs, which we consider to be our event days. ${ }^{12}$ We categorize the events according to several criteria: WHO Statement, WHO Disease Outbreak News, Approval, Gvt. Order, Gvt. Order Cancel, Research Funding and Statement. Events that are considered to be a WHO Statement ${ }^{13}$ or WHO Disease Outbreak News ${ }^{14}$ are obtained from the official website of WHO. All the other events are obtained through a rigorous online search.

WHO Statements is an official statement communicated to the public with regard to any new and substantial information related to a certain disease. For instance, on August 8th 2014 the "Statement on the 1st meeting of the IHR Emergency Committee on the 2014 Ebola outbreak in West Africa" informed on the current state of the Ebola disease outbreak. Additionally, the emergency committee stated that conditions for a PHEIC have been met and provided advice to address the Ebola outbreak in the affected countries. Typically, the mass media uses such WHO Statements to communicate the news to a greater public.

WHO Disease Outbreak News, on the other hand, are to some extent regular updates on the current situation and include, for instance, news about first cross-border transmissions of a disease. In case of the SARS outbreak in 2003, there were periods of daily updates, while news on the 2009 Influenza A(H1N1) outbreak were covered on a weekly basis. We recognize that all regularly spaced updates may be anticipated by stock market investors and may be priced in prior to the actual update. For this reason, our sample of announcements comprises only those updates that documented first-time cross-border transmissions. Such strategy helps ensure the independence of subsequent announcements, insofar as cross-border transmissions of pandemic diseases occur unpredictably. In case of SARS, we observe a rapid spread across countries within the first two months. ${ }^{15}$ In total, 29 countries were affected by the disease. In case of Influenza A(H1N1), the official list counts more than 214 countries and overseas territories or communities as of August 1st 2010. The disease spreads quickly and our list includes a sizable number of first cross-border transmission dates (around 50).

\footnotetext{
${ }^{12}$ Notice that WHO announcements and disease-based news released on week-end days are assumed to have an effect on Monday.

${ }^{13}$ http://www.who.int/mediacentre/news/statements/en

${ }^{14}$ http://www.who.int/csr/don/en

${ }^{15}$ Occasionally there were false alarms. Some countries were temporarily included and subsequently removed from the list of affected countries (if a SARS outbreak could not be confirmed in retrospect). We also included such false alarm dates in our analysis since the public is likely to take the information as a fact without questioning its reliability at the time the news is published.
} 
For Polio, we abstain from identifying first outbreak dates as there are only ten event dates in total. Considering Ebola, we count ten cross-border transmissions in total. However, the disease was still not under control at the time this paper was written.

In addition to WHO Statements and WHO Disease Outbreak News, we include release dates of official statements provided by government ministries and agencies as well as individual publicly traded companies. Newly developed vaccines are subject to governmental approval and a positive feedback might have a substantial impact on the share price of the vaccine producing company as well as on its competitors/followers. We use official press release dates provided by the website of the US Department of Health and Human Services (HHS) and label them Approval. Please note that this category is only relevant for Influenza A(H1N1). For SARS and Ebola, vaccines are still in development while potent Polio vaccines have existed for decades. Gvt. Order and Gvt. Order Cancel refer to government purchases of vaccine and subsequent cancellations of orders. Again, these dates refer to the Influenza A(H1N1) outbreak only. In the case of the SARS outbreak, companies were granted research funding to develop a potent vaccine. We label the official dates of funding announcements Research Funding. The category Statement subsumes different, potentially influential, statements provided by government officials and companies referring to the current situation with regard to a disease. All DRNs are classified and summarized in Table A.2.

\subsection{Descriptive Statistics}

The stock market data - end-of-trading-day prices and market values - are retrieved from Thomson Reuters Datastream. The cross section includes 102 pharmaceutical companies that are listed either on the New York Stock Exchange (NYSE) or NASDAQ. In addition, we retrieve the $S \& P 500$ Information Technology index. For non-US based companies, we use the data on American Depository Receipts (ADRs). This gives rise to a 12-year period with 3097 trading days, from January 2003 to November 2014. To test for the impact of DRNs on pharmaceutical stock returns, we employ the rates of return on a variety of portfolios comprising pharmaceutical stocks. Specifically, we construct four benchmark "phar- 
maceutical portfolios". The first is an equally-weighted portfolio (EW). ${ }^{16}$ The second is a value-weighted portfolio of all pharmaceutical stocks with time-varying market-value based weights $(\mathrm{VW})$. The third portfolio is a constant-value-weighted portfolio accounting for the 10 largest pharmaceutical stocks (TOP). The fourth is a constant-value-weighted portfolio of 10 smallest pharmaceutical stocks (BOTTOM). The value-weighted portfolio emphasizes the role of large companies as opposed to small companies. The TOP portfolio illustrates a real-world situation where investors are constrained by cardinality constraints. The BOTTOM portfolio addresses our Hypothesis 4 stated in the next section. Finally, the inclusion of S\&P500 Information Technology - a standardized and tradable diversified portfolio of stocks - seeks to project our hypotheses on sectors other than the pharmaceutical. In doing so, we show that the DRN positive sentiment spreads to other sectors and confirm that the breadth of sentiment is not confined to the pharmaceutical industry only.

We then compute continuously-compounded day-to-day percentage returns on the aforementioned portfolios, $R_{E W}, R_{V W}, R_{T O P}, R_{B O T T O M}$ and $R_{S P 500}^{I T}$, respectively. The descriptive statistics are summarized in Table 2.

Over the sample period, the mean return on the value-weighted portfolio of pharmaceutical stocks with time-varying weights (VW), 0.0549\%, was considerably greater than the mean of the remaining portfolios. The median follows a similar pattern with one notable exception, where the difference between the mean and the median (and hence the ensuing asymmetries in the probability density function) is largest for the EW portfolio. The range of variation between the maximum and the minimum returns is greatest for the S\&P500 IT portfolio (11.46\% and $-9.67 \%$, respectively) and lowest for the VW portfolio $(10.17 \%$ and $-6.52 \%$, respectively). The BOTTOM portfolio has the highest idiosyncratic risk, as measured by the standard deviation $(1.63 \%)$, whereas the TOP portfolio is the least risky to invest (1.03\%). Moreover, portfolio returns are negatively skewed, with an exception of the VW portfolio. The negative skewness implies that large negative returns are more likely than large positive returns, whereas the converse is true for the positively skewed returns. Furthermore, returns on the five portfolios are leptokurtic, where the coefficient of excess

\footnotetext{
${ }^{16}$ The equally-weighted portfolio draws on the literature that studies the optimality of portfolios of naïve investors (De Miguel et al., 2009)
} 
Table 2: Descriptive statistics

\begin{tabular}{lcccc|c}
\hline \hline Statistic & $E W$ & $V W$ & $T O P$ & BOTTOM & $S P 500^{I T}$ \\
\hline Mean (\%) & 0.0077 & 0.0549 & 0.0159 & -0.0125 & 0.0366 \\
Median (\%) & 0.0405 & 0.0586 & 0.0209 & 0.0000 & 0.0559 \\
Maximum (\%) & 10.5582 & 10.1711 & 10.3673 & 8.2638 & 11.4610 \\
Minimum (\%) & -7.1160 & -6.5238 & -7.7975 & -11.2926 & -9.6701 \\
Std. Dev.(\%) & 1.2198 & 1.1391 & 1.0262 & 1.6259 & 1.3702 \\
Skewness & -0.3194 & 0.0210 & -0.1041 & -0.1746 & -0.0439 \\
Excess Kurt. & 4.5993 & 4.6354 & 9.0512 & 2.6647 & 9.3379 \\
Jarque-Bera & 2782.39 & 2772.99 & 10577.2 & 931.996 & 5184.43 \\
& $(0.0000)$ & $(0.0000)$ & $(0.0000)$ & $(0.0000)$ & $(0.0000)$ \\
Ljung-Box $Q_{5}$ & 29.581 & 8.2820 & 24.890 & 12.497 & 21.378 \\
& $(0.0000)$ & $(0.1414)$ & $(0.0001)$ & $(0.0286)$ & $(0.0007)$ \\
Ljung-Box $Q_{5}^{2}$ & 1069.197 & 667.071 & 1260.68 & 167.730 & 802.233 \\
& $(0.0000)$ & $(0.0000)$ & $(0.0000)$ & $(0.0000)$ & $(0.0000)$ \\
Observations & 3097 & 3097 & 3097 & 3097 & 3097 \\
\hline \hline
\end{tabular}

Notes: This table summarizes the descriptive statistics (mean, median, maximum, minimum, standard deviation, skewness, excess kurtosis, the Jarque-Bera statistic, Ljung-Box test statistics for returns and returns squared) of continuously compounded day-to-day percentage returns on five investment portfolios. $E W$ denotes returns on an equally-weighted portfolio of pharmaceutical stocks. $V W$ denotes returns on a (time-varying) value-weighted portfolio of pharmaceutical stocks. TOP denotes returns on a constant-value-weighted portfolio of 10 largest pharmaceutical firms. BOTTOM denotes returns on a constantvalue-weighted portfolio of 10 smallest pharmaceutical stocks. $S P 500^{I T}$ denotes returns on the $S \& P$ Information Technology stock index. $Q_{5}$ denotes the Ljung-Box test statistic for the fifth-order cumulative autocorrelation of stock returns, and $Q_{5}^{2}$ denotes the Ljung-Box test statistic for the fifth-order cumulative autocorrelation of returns squared. The p-values are provided in round parentheses. The table also provides the p-values for the significance tests of the Jarque-Bera and Ljung-Box statistics. We use daily data for the period 01/01/2003 - 11/13/2014 (a total of 3097 observations).

kurtosis is greater than zero. A high value of excess kurtosis contributes to the observed non-normality of returns for the five portfolios, as measured by the Jarque-Bera test statistic. The Ljung-Box test statistic provides evidence of serial correlation in (squared) returns. Therefore, our regression-based methodology in Section 4.3 is designed so as to account for heteroscedasticity.

\section{Hypotheses and Methodology}

\subsection{Testable Hypotheses}

This section outlines testable hypotheses for pharmaceutical stock returns around DRNs. DRNs may give rise to two conflicting sentiment effects, the DRNs positive effect and the fear effect. In this respect, Kaplanski and Levy (2012) document a "negative and significant war sentiment effect" during the Yom Kippur war in Israel, and a positive and significant "holiday sentiment effect". Firstly, DRNs may lead to anxiety, bad mood and pessimism 
among the general public and stock market investors, associated with a panic effect generated by overemphasized media coverage of pandemic diseases. In this scenario, anxiety and fear spread across different stock market sectors and may instigate a drop in the pharmaceutical stock prices. Our first hypothesis states that the investor's fear gauge, provoked by DRNs, may lead to a decrease in the rate of return on pharmaceutical companies' stocks.

Hypothesis 1. DRNs may lead to bad mood among investors which negatively affects portfolio returns of pharmaceutical stocks.

Secondly, globally dangerous diseases may be perceived by stock market investors as a profitable investment opportunity. Investors might unreasonably anticipate that a disease will trigger an increase in $\mathrm{R} \& \mathrm{D}$ expenditure by pharmaceutical companies. This development generates a positive sentiment and hence raises demand for pharmaceutical companies' stocks. As a result, portfolio valuation increases. Thus, our second hypothesis predicts a positive relation between DRNs and returns on pharmaceutical stocks.

Hypothesis 2. DRNs have a positive effect on portfolio returns of pharmaceutical stocks.

Our third hypothesis underlies the assumption that investors initially underreact to an announcement of a globally dangerous disease but they overreact thereafter, wherein the degree of overreaction depends on the announcement's relative salience as measured by media coverage (Palomino et al., 2009). The larger the information salience of an announcement the faster the contents are incorporated into the share prices (Klibanoff et al., 1998). Within the pharmaceutical industry, considerable media coverage can cause significant changes in stock prices through continuous overreporting, even though no genuinely new information becomes available to the market (Huberman and Regev, 2001). Thus, motivated by the existing literature and the observed inflow of information around PHEIC alerts (see Figure 1), we further hypothesize that, after the event, the positive sentiment of stock market investors remains at an elevated level.

Hypothesis 3. DRNs have a persistent effect on portfolio returns of pharmaceutical stocks. Such persistence is consistent with an inflow of disease-related information in the stock market. 
Our fourth hypothesis builds on the notion that investor sentiment should affect stronger small stocks relative to large stocks (see, for instance, Brown and Cliff, 2005). Therefore, we expect that on and after the event day, investor sentiment will be potentially stronger for small pharmaceutical firms than for large firms. This hypothesis is supported by recent studies suggesting that stocks of small firms are mainly held by local investors who tend to be largely influenced by specific events (see also Edmans et al., 2007). Furthermore, even though large pharmaceutical companies act as forerunners of $R \& D$ activities, it may be less costly for small pharmaceuticals to act as followers in the development of new drugs. ${ }^{17}$ However, vaccine production requires more costly and sophisticated technologies than drug production (Hinman et al., 2006). The cost of new vaccines places a constraint on small pharmaceutical firms. As a result, they are likely to contribute to the development of new vaccines less than large firms.

Hypothesis 4. DRNs have a greater effect on stock returns of small companies relative to large companies.

Two commonly employed methodologies - the event-study and regression-based - are used to test the aforementioned hypotheses.

\subsection{Event Study Methodology}

In the spirit of traditional event studies, we begin our analysis by computing cumulative abnormal returns (CARs) around DRNs. The abnormal returns are defined as the difference between the observed rate of return of a pharmaceutical portfolio and its ex-post expected rate of return over the whole length of the event window. The expected rate of return is estimated based on the Fama-French three-factor model ${ }^{18}$. We choose an event window length to cover 14 days prior and 14 days after DRNs. The estimation window for the model is 252 days long.

\footnotetext{
${ }^{17}$ Despite the well-documented first-mover advantage in the pharmaceutical industry, "under the current law, the chemical formula and the efficacy of the cure as established by clinical trials are made available for competitors essentially for free" (Boldrin and Levine (2013), Page 13). When patents expire, low-cost generics are immediately introduced in the market.

${ }^{18}$ The daily data for the factors SMB, HML, and the excess return on the market were obtained from Kenneth French's website (http://mba.tuck.dartmouth.edu/pages/faculty/ken.french).
} 
In our sample, we observe temporal clustering of DRNs. This means that if all DRNs were taken into account, the CARs would suffer from overlapping event windows. For this reason, our CAR calculations include only a subset of all available DRNs. The DRNs are selected according to the following two criteria. The first selection procedure, labelled LAST EVENT, chooses a DRN only if it is not followed by other DRNs within 28 days after its occurrence. FIRST EVENT, on the other hand, selects the DRNs in a chronological order. It starts with the first DRN in the sample, ignores all DRNs showing up in the proximate 28 days, takes the next DRN in succession, ignores the following 28 days, and so on. This iteration proceeds until the whole sample is exhausted.

For illustration, assume there are five DRNs taking place at dates $\tau_{0}, \tau_{1}, \tau_{2}, \tau_{3}$, and $\tau_{4}$ where $\tau_{1}, \tau_{2}$, and $\tau_{3}$ are temporally clustered. Then, LAST EVENT uses DRNs for CAR calculation occurring on days $\tau_{0}, \tau_{3}$, and $\tau_{4}$ and FIRST EVENT chooses $\tau_{0}, \tau_{1}$, and $\tau_{4}$. The top two panels in Figure 2 illustrate graphically these two simple examples.

\subsection{Regression-Based Methodology}

Following existing empirical studies (see Kamstra et al., 2003; Edmans et al., 2007; Kaplanski and Levy, 2010a,b; Curatola et al., 2016), to evaluate the impact of DRNs on pharmaceutical stock returns, and to identify the negative fear effect, we implement the following regression model:

$$
R_{p, t}=\beta_{0}+\sum_{i=1}^{5} \beta_{1, i} R_{p, t-i}+\sum_{i=1}^{4} \beta_{2, i} D_{i, t}+\beta_{3} D_{t}^{T A X}+\beta_{4} E_{t}+\beta_{5} F I_{t}+u_{p, t}
$$

where $R_{p, t}$ is the daily rate of return on a portfolio of pharmaceutical stocks $p, \beta_{0}$ is the regression intercept, $R_{p, t-i}$ are lagged dependent variables. $D_{1}, D_{2}, D_{3}, D_{4}$ are dummy variables for Monday, Tuesday, Wednesday, and Thursday, respectively, and $D_{t}^{T A X}$ is a dummy variable for the first five days of the taxation year. Further, $E_{t}$ represents the DRNs effect variable, $F I_{t}$ denotes a fear index, and $u_{p, t}$ is an error term. In line with existing studies, the VIX is used to proxy the investment fear index also known as "investor fear gauge" (see Whaley, 2009). ${ }^{19}$ Specifically, in the spirit of Bloom (2009), our fear indicator is a dummy

\footnotetext{
${ }^{19}$ We consider the VIX an adequate proxy as the correlation between the 252-days rolling standard devi-
} 
variable that takes on value 1 when the US stock market volatility exceeds by more than 1.65 standard deviations the Hodrick-Prescott detrended $\left(\lambda=1600 *(365 / 4)^{4}\right)$ mean of the stock-market volatility series (i.e., the raw VIX), and 0 otherwise. ${ }^{20}$

The coefficient $\beta_{4}$ captures the contemporaneous effect of DRNs on the portfolio rate of return. It should be noted that the majority of DRNs (85\%) is published by the WHO which is headquartered in Geneva, Switzerland. Due to different time zones, we assume that the US stock market reacts on the day of DRNs publication. Further, previous days' rates of return, $R_{p, t-i}$, variables are embedded in our main regression to account for possible serial correlation. We choose five lagged returns to be sure that all serial correlations have been accounted for. The dummy variables for the days of the week are employed to account for the so-called "Monday effect".

To account for a possible positive sentiment effect on the days following DRNs, or differently, for a possible reversal effect, we run also the following regression:

$$
R_{p, t}=\beta_{0}+\sum_{i=1}^{5} \beta_{1, i} R_{p, t-i}+\sum_{i=1}^{4} \beta_{2, i} D_{i, t}+\beta_{3} D_{t}^{T A X}+\sum_{i=0}^{I} \beta_{4, i} E_{t-i}+\beta_{5} F I_{t}+u_{p, t}
$$

\section{Results}

\subsection{Event Study Methodology}

Figure 2 depicts the CARs around the event date. The black solid (dashed) line illustrates the LAST EVENT (FIRST EVENT) approach. The LAST EVENT approach gives rise to positive abnormal returns following the event day for the EW and the BOTTOM portfolio. The increase prior to the event can be attributed to the sensitivity of the LAST EVENT approach to the contiguous (preceding) events in the overlapping window. The FIRST EVENT approach points to an increase in returns of the EW and BOTTOM portfolios on the event day. This increase is rather persistent on the days following the event, thus, confirming that also those DRNs that were discarded in the CAR calculation had a positive ation of the S\&P 500 index and the pharma portfolios is rather high (average correlations are reported in parentheses): EW (0.79), VW (0.72), TOP (0.82), BOTTOM (0.78).

${ }^{20}$ Notice that the fear effect $F I_{t}$ overlaps with the sentiment effect generated by DRNs in 119 out of 146 cases. 
impact on pharmaceutical stock returns. The results are less supporting for the VW and TOP portfolios. We stress that the event study results are weaker than the regression results reported in the next section due to the fact that only 33 out of 146 DRNs were employed in the CAR analysis. In general, EW LAST/FIRST (VW, TOP, BOTTOM) experienced in $27 \% / 30.7 \%(34.6 \% / 42.3 \%, 38.4 \% / 42.3 \%, 53.8 \% / 50 \%)$ of all event cases a significant CAR at a $10 \%$ level. Still, our CAR analysis provides evidence supporting the persistent (positive) sentiment effect hypothesis. One could anticipate that the SMB factor in the three-factor Fama-French model already captures some of the effect of investment sentiment, biasing the estimate of CARs. Indeed, if investors holding smaller stocks become more optimistic, then the SMB factor increases, and the cumulative abnormal return decreases. We also computed the CARs by employing the excess return on the market in a one-factor model. ${ }^{21}$ The unreported results suggest more pronounced CARs for the BOTTOM portfolio. Overall, our event study analysis reveals a positive and persistent effect of DRNs on stock returns of pharmaceutical companies.

\subsection{Regression Analysis}

Results examining the effect of the fear gauge and DRN on the pharmaceutical stock market returns are reported in Table 3. Panel A documents our main findings that result from incorporating all events in the regression analysis. For robustness purposes, we also rerun our model on a subsample of DRNs by employing WHO-related announcements only (see Panel B). Consistently with the Investor Fear Gauge Hypothesis (Hypothesis 1), a negative and significant effect of the fear gauge index is obtained. This effect is robust across the five portfolios. The estimated coefficient $\beta_{5}$ ranges from -0.1378 (TOP portfolio) to -0.2056 (VW portfolio). Thus, the effect of investor fear gauge is strongest for diversified portfolios of stocks and weakest for large firms. Further, the DRNs variable effect is always positive and generally significant at the 5\% significance level, vindicating Hypothesis 2 (Positive Sentiment Hypothesis). The coefficient estimate ranges from 0.1781 (VW) to 0.3877 (BOTTOM). Thus, in the wake of DRNs, stock returns increase within the range between 18 and 39 basis

\footnotetext{
${ }^{21}$ In the one-factor model, EW LAST/FIRST (VW, TOP, BOTTOM) experienced in $42.3 \% / 42.3 \%$ $(46.1 \% / 50 \%, 46.2 \% / 50 \%, 53.9 \% / 50 \%)$ of all event cases a significant CAR at a $10 \%$ level.
} 
Figure 2: Cumulative Abnormal Returns

\section{Pharmaceutical Portfolios}

\section{LAST EVENT}
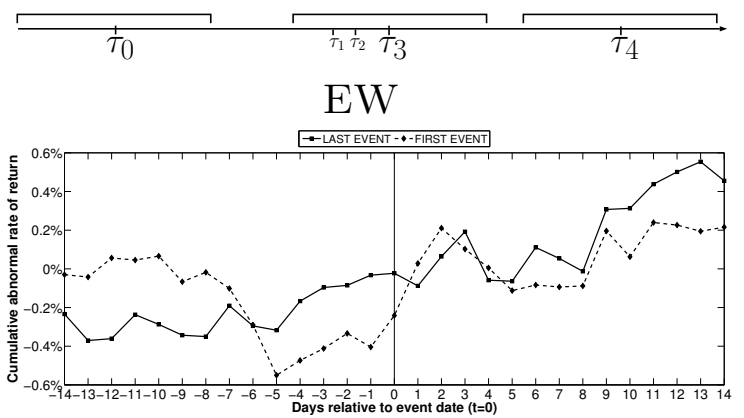

VW

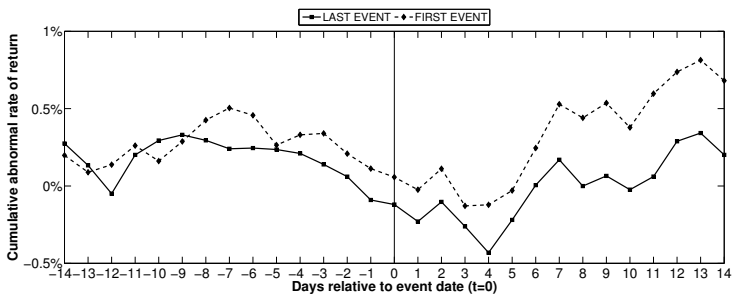

FIRST EVENT
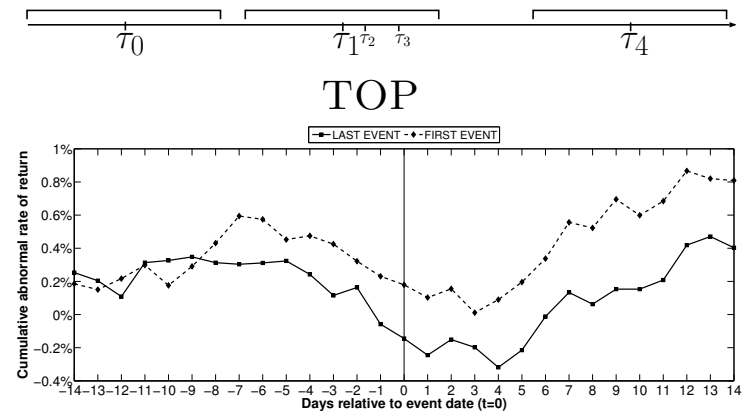

BOTTOM

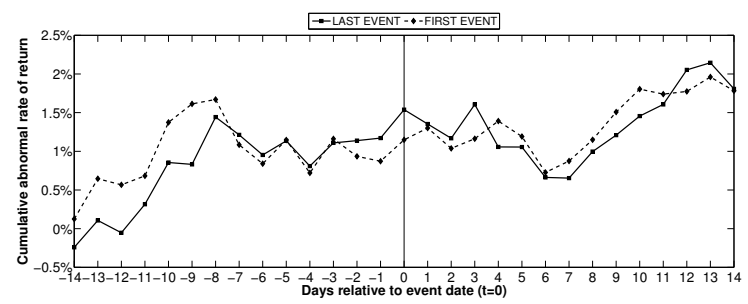

Notes: This figure depicts the average cumulative residuals around the event date $(t=0)$ for pharmaceutical portfolios EW, VW, TOP, and BOTTOM . The residual on day $t$ is calculated as the difference between observed rate of return and the ex-post expected rate of return on day $t$. The three-factor model is $r_{t}=\alpha+\beta_{1}\left(r_{m, t}-r_{f}\right)+\beta_{2} s m b_{t}+\beta_{3} h m l_{t}+\epsilon_{t}$, where $r_{t}$ is the pharmaceutical portfolio return and $r_{m, t}-r_{f}, s m b_{t}$ and $h m l_{t}$ are Fama-French factors. The estimation window is 252 days. The solid (dashed) line represents the LAST (FIRST) EVENT approach when estimating the CARs. This ensures that event windows are non-overlapping. The top two panels illustrate the two different estimation procedures graphically. The LAST (FIRST) EVENT approach includes event days $\tau_{0}, \tau_{3}$ and $\tau_{4}\left(\tau_{0}, \tau_{1}\right.$ and $\left.\tau_{4}\right)$ in the estimation procedure. The events occurred during a 12-year period (March 2003 to December 2014) which includes 33 event days with non-overlapping event windows.

points. This is an interesting finding, insofar as pandemic diseases, such as Ebola, may not actually spread in the US. However, as suggested by existing studies, investor decisions can be guided by sentiment. Paradoxically, while globally dangerous diseases may impose non-negligible costs on the economy and may potentially lead to the depletion of resources, DRNs can produce an optimistic view and a positive sentiment effect among stock market investors located in the US. The investors unreasonably anticipate that pharmaceutical companies whose stocks or ADRs are listed on the NYSE or NASDAQ will invest in R\&D and, potentially, raise their future cash flows. However, they overlook the fact that the patent system constrains investment and productivity growth in the pharmaceutical industry (Boldrin and Levine, 2013). At the same time, they underestimate the probability that vaccines and medicines are not necessarily effective (Shortridge, 2004). The results unambiguously indi- 
cate that stock market investors should buy stocks when an outbreak of a pandemic disease is announced. Moreover, investment in a relatively diversified portfolio of stocks (such as EW or VW) when a pandemic disease is announced yields a lower return than investment in a portfolio of small stocks (such as BOTTOM), ceteris paribus. ${ }^{22}$ This finding supports Hypothesis 4 wherein small stocks respond stronger to investor sentiment than large stocks. This result resonates well with Brown and Cliff (2005) and Edmans et al. (2007).

Table 4 further shows that the investor fear gauge has the smallest (largest) effect (in absolute value) for the TOP (VW) portfolio (-0.1481 and -0.2163 , respectively). The investor fear gauge reflects investor pessimism regarding portfolio investment, which has a negative effect on stock prices and returns of pharmaceutical companies. This result confirms Hypothesis 1, which predicts a negative relation between investor fear gauge and returns on pharmaceutical companies' stocks. It is qualitatively similar to results reported by Kaplanski and Levy (2012), wherein the investor fear gauge provoked by the Yom Kippur war is responsible for a negative effect on the stock market return of the Tel Aviv Stock Exchange. Table 4 also indicates that the investor's sentiment effect is positive and persistent. We use six lags of DRNs to capture the persistence. We test the combined effect of the contemporaneous and lagged DRNs on pharmaceutical stock returns. To this end, we test for the significance of the coefficient sum $\sum_{i=0}^{I} \beta_{4, i}$. Entries related to this coefficient sum highlight that the DRNs positive sentiment effect is stronger among small pharmaceutical firms (0.8169) and is weaker for the value-weighted portfolio (0.4860). In all cases, the coefficient is significant at $1 \%$ level. Results in Table 4 build on the assumption that the DRNs positive sentiment effect will last for six trading days due to a continuous flow of information in the stock market. Indeed, as suggested by Figure 1, the number of media articles remains above average during six days in the aftermath of a PHEIC event. The estimated lagged effects are also consistent with Kaplanski and Levy (2010b), who argue that the announcement typically receives headlines several days after the event. The estimation results for the five portfolios show a positive and significant effect (at the significance level of $5 \%$ or higher) for at least six working days after DRNs is released. Thus, our results also support Hypothesis

\footnotetext{
${ }^{22}$ It should also be noted that either due to lower expenses related to sub-contracting (Assid et al., 2015) or less costly imitation of larger pharmaceutical companies (Boldrin and Levine, 2013), small pharmaceutical stocks can potentially generate higher returns than large stocks.
} 
3 (i.e., Persistent Sentiment Hypothesis), wherein the positive sentiment remains significant several days after the DRNs. This result agrees with Huberman and Regev (2001) who underscore the importance of the information salience of a breakthrough in bio-pharmaceutical research. Taking together contemporaneous and lagged effects, there is unequivocal evidence that DRNs has a positive and significant (either contemporaneous or lagged) effect on the pharmaceutical stock prices.

Finally, it is worth noting that fear gauge and DRNs not only can provoke changes in the pharmaceutical stock prices, but also in the S\&P500 Information Technology stock index - an industry unrelated to globally dangerous diseases - thus lending further support to the investment sentiment effect. Specifically, our results indicate that fear gauge (DRNs) has always a negative (positive) and significant effect on returns of the S\&P500 Information Technology stock index. This result shows that the investor sentiment effect can be widespread across various industries in the economy and lead to profitable trading strategies in the stock market.

It is worth noting that our research findings were further validated by a number of robustness checks. First, we sought to ascertain the extent to which investor sentiment can spread to other sectors of the economy and even to other countries. In this regard, the presence of investor sentiment was identified in the S\&P500 Industrials portfolio - an industry seemingly unrelated to globally dangerous diseases. The impact of fear gauge and DRNs was also tested on regions that were directly affected by globally dangerous diseases. In particular, the estimation results show a negative (positive) and significant effect of fear gauge (DRNs) on returns on the MSCI Emerging Markets stock market index. Second, to account for the presence of conditional heteroscedasticity in daily stock returns, our regression methodology was extended to include a battery of GARCH specifications. As in the benchmark methodology, results show a negative (positive) and significant effect of fear gauge $(\mathrm{DRN})$ on pharmaceutical stock return, endorsing the main findings. Third, as a complementary exercise, we varied the number of lags in Eq. (2). The estimation results broadly support Hypothesis 3. Fourth, we performed all our regressions excluding the control variables (i.e., with the DRNs and fear gauge variables only). Again, the main findings can be upheld. The general conclusion that can be drawn from these robustness checks is 
that investor sentiment, triggered by globally dangerous diseases, is neither confined to the pharmaceutical industry nor is model specific. By contrast, the presence of investor sentiment is robust to the type of activity, the geographical scope and the various methodological underpinnings. ${ }^{23}$

${ }^{23}$ All the additional checks are not reported but are available from the authors upon request. 


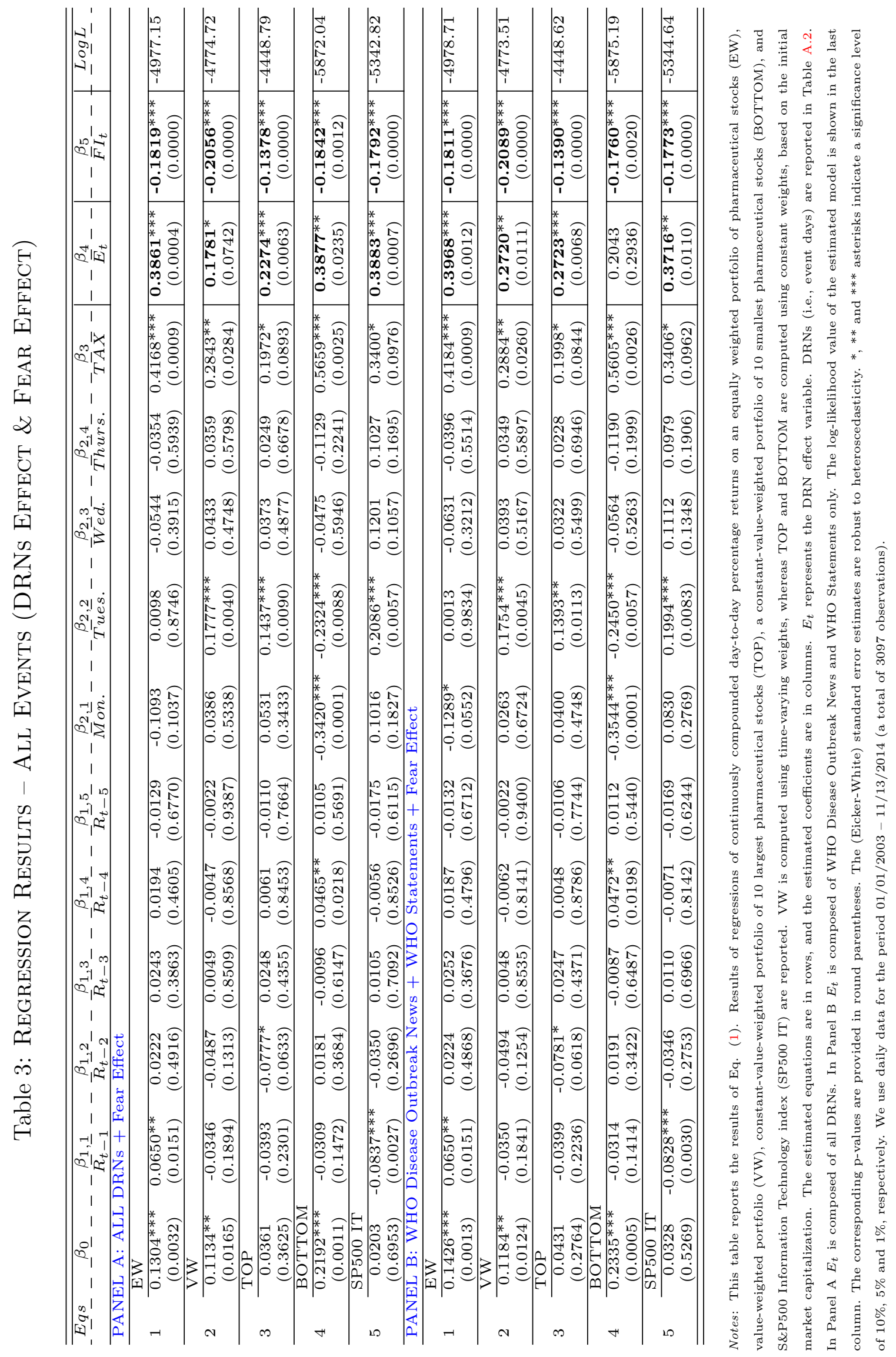



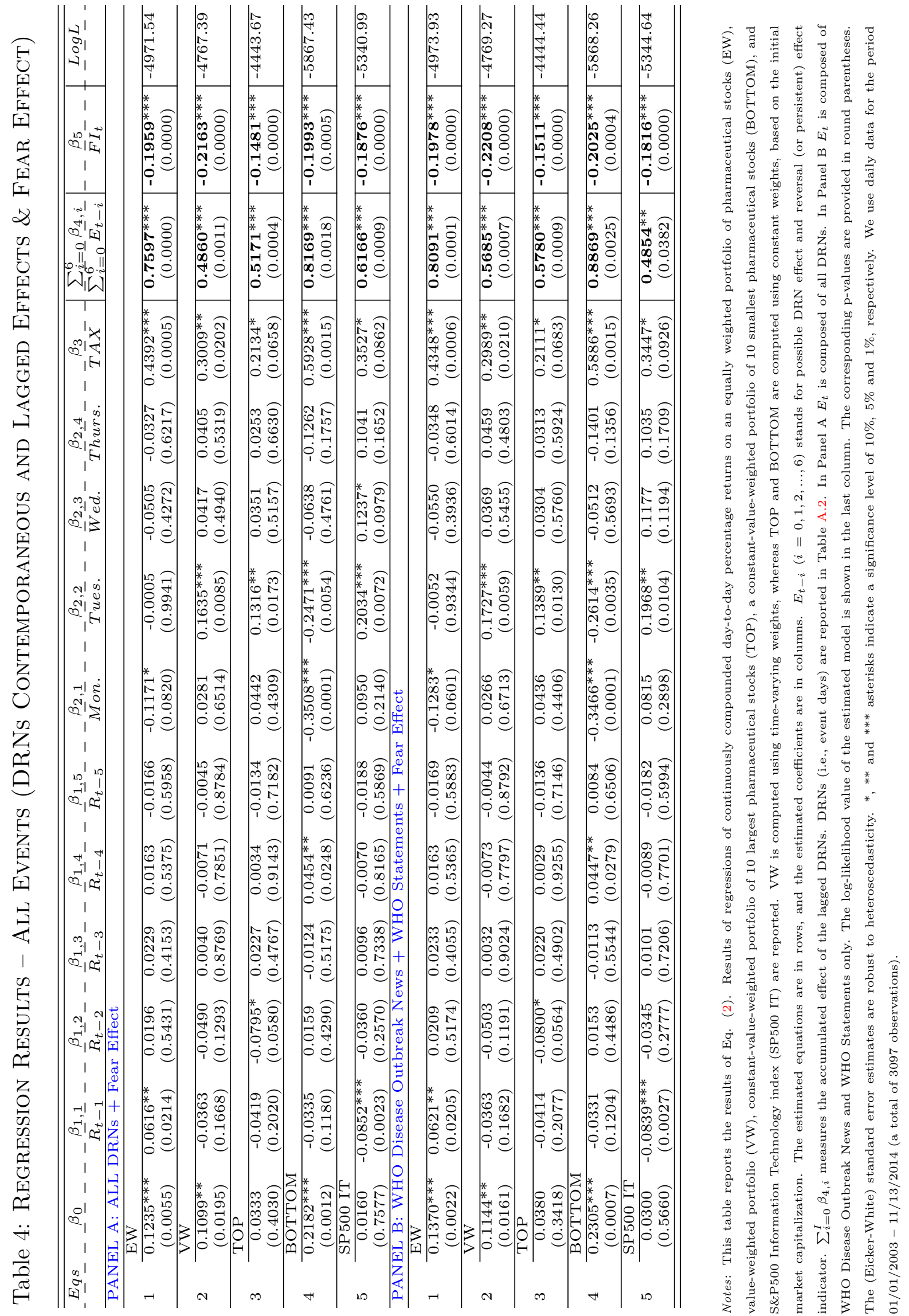


\section{$6 \quad$ Exploiting Sentiment and Fear Effects}

Based on the empirical evidence reported in the previous sections, we assume that an investor is willing to exploit both sentiment and fear effects in response to DRNs by reallocating her wealth to pharmaceutical stocks. For this purpose, we consider a zero-cost strategy. On event days that coincide with high-volatility periods, as measured by the fear index, the zero-cost spread portfolio takes a $100 \%$ long position in one of the four above mentioned pharmaceutical portfolios and a 100\% short position in the VIX. We let the holding period of the spread portfolio vary between one (1D) and three days (3D). To eliminate timinginconsistencies, the trade is initiated at closing prices of the event day. This procedure ensures that no trade precedes a DRN publication on any given event day. ${ }^{24}$ Table 5 reports the strategies' average performance. In Panel A all DRNs are taken into account while Panel B considers only the WHO-related subsample. The 1D strategy does not yield a significant performance for all four pharmaceutical portfolios. Differently, a holding period of two or three days is remarkably profitable. Such profitability is higher in the case of the EW and BOTTOM portfolios.

The longer term profitability of overweighting pharmaceutical stocks and underweighting the VIX is illustrated in Figure 3. Differently from the strategies presented in Table 6, we assume in the following full exposure to the stock market. That is, during tranquil times investor's wealth is invested in the market portfolio, which is proxied by the S\&P500. On event days that coincide with high-volatility periods, the investor reallocates her funds by going $150 \%$ long in a pharmaceutical portfolio and 50\% short in the VIX index and holds her position between one (1D) and three (3D) days. The depicted outperformance is calculated as the difference between the cumulative performance of a trading strategy and the market portfolio. A visual inspection suggests a similar performance between the VW and TOP portfolios while EW and BOTTOM are the more profitable strategies for all three investment horizons.

For robustness purposes, we ignore the fear effects and consider a simple buy-and-hold

\footnotetext{
${ }^{24} \mathrm{~A}$ more precise approach would involve the exact publication time of the news in a given country and by taking into account the time zone difference between the US and the respective country. Unfortunately, the majority of DRNs does not have a time stamp. Nevertheless, our trading strategy is consistent in timing for those DRNs that are accompanied with an exact publication time.
} 
Table 5: Trading Strategy

\begin{tabular}{|c|c|c|c|c|}
\hline \multicolumn{5}{|c|}{ PANEL A: (ALL DRNS) } \\
\hline & $E W$ & $V W$ & TOP & ВОTТОМ \\
\hline \multirow[t]{2}{*}{ 1D } & 0.518 & 0.3755 & 0.4208 & 0.3941 \\
\hline & $(0.5208)$ & $(0.5085)$ & $(0.5036)$ & $(0.5226)$ \\
\hline \multirow[t]{2}{*}{$2 \mathrm{D}$} & $1.6302^{* *}$ & $1.2548^{* *}$ & $1.2544^{* *}$ & $1.4261^{* *}$ \\
\hline & $(0.7754)$ & $(0.7551)$ & $(0.7386)$ & $(0.7592)$ \\
\hline \multirow[t]{2}{*}{$3 \mathrm{D}$} & $1.913^{* *}$ & $1.433^{* *}$ & $1.4542^{* *}$ & $1.9172^{* * *}$ \\
\hline & $(0.8539)$ & $(0.8076)$ & $(0.8006)$ & $(0.8063)$ \\
\hline \multicolumn{5}{|c|}{ PANEL B: (WHO Disease OUtbreak NeWs + WHO Statements) } \\
\hline & $E W$ & $V W$ & TOP & ВOTTOM \\
\hline \multirow[t]{2}{*}{ 1D } & 0.4991 & 0.3831 & 0.4181 & 0.424 \\
\hline & $(0.5725)$ & $(0.5618)$ & $(0.5555)$ & $(0.5877)$ \\
\hline \multirow[t]{2}{*}{$2 \mathrm{D}$} & $1.6275^{* *}$ & $1.2644^{*}$ & $1.2491^{*}$ & $1.3749^{*}$ \\
\hline & $(0.8505)$ & $(0.8368)$ & $(0.8174)$ & $(0.8572)$ \\
\hline \multirow[t]{2}{*}{$3 \mathrm{D}$} & $2.0802^{* *}$ & $1.6035^{* *}$ & $1.6335^{* *}$ & $2.1461^{* *}$ \\
\hline & $(0.9783)$ & $(0.9301)$ & $(0.9224)$ & $(0.9296)$ \\
\hline
\end{tabular}

Notes: This table presents the average performance (in \%, standard deviations are in parentheses) of a spread portfolio that is invested $100 \%$ long in a pharmaceutical portfolio and $100 \%$ short in VIX. Long and short positions are taken only during high-volatility states of the world (as indicated by the Fear Index) and using closing prices of the DRN day. The holding period of the portfolio varies between one (1D) and three days (3D). In Panel A the trading strategy is based on all DRNs. In Panel B the trading strategy is based on WHO Disease Outbreak News and WHO Statements only. The trading period runs from January 2003 to November 2014 (3097 trading days). Standard errors are reported in parentheses. *, ** and *** denote significance of a two-tailed t-Test at the $10 \%, 5 \%$ and $1 \%$ level, respectively.

strategy that initiates a long position in a pharmaceutical portfolio at the closing prices of an event day and holds it for 14 days. The unreported results confirm that also this strategy would have yielded a positive outperformance over the market. ${ }^{25}$

Overall, we find that investment strategies exploiting sentiment and fear effect related to DRNs lead to higher profitability. Once again, this result is most pronounced for the BOTTOM portfolio confirming that sentiment tends to have a greater effect on small stocks.

\footnotetext{
${ }^{25}$ The EW (VW, TOP, BOTTOM) portfolio has on average a $1.6 \%(0.7 \%, 0.3 \%, 1.7 \%)$ higher performance than the S\&P500 during a 14 day period.
} 


\section{Figure 3: Outperformance of DRNs and Fear Effects Strategies}

$1 \mathrm{D}$

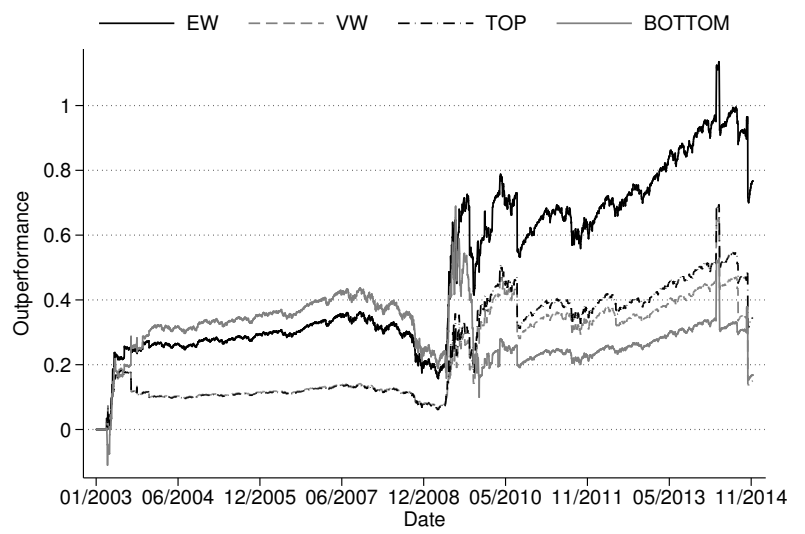

$2 \mathrm{D}$

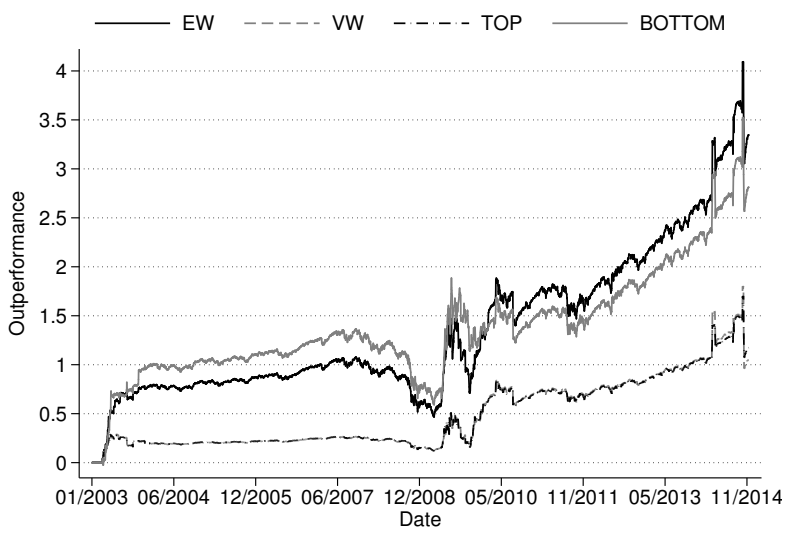

$3 \mathrm{D}$

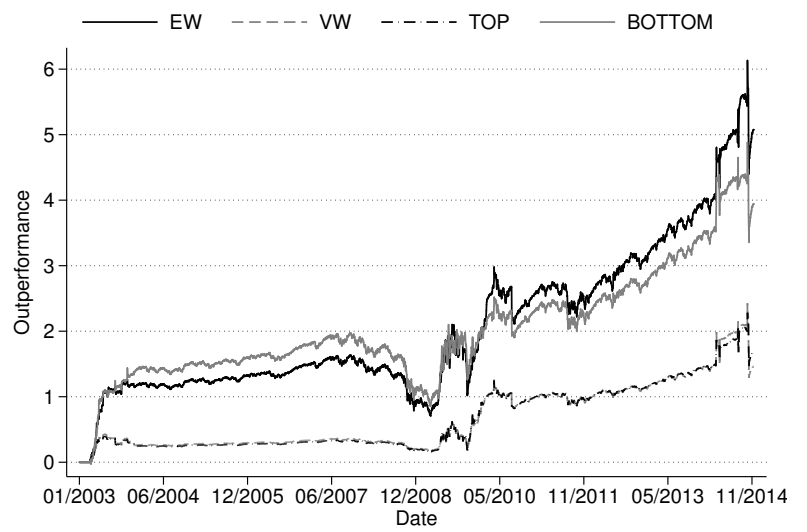

Notes: This figure depicts the outperformance of portfolios that follow DRNs-based trading strategies. The strategies initiate a $150 \%$ long position in a pharmaceutical portfolio (using closing prices of the DRN day) and a $50 \%$ short position in the VIX on those event dates that coincide with high-volatility states of the world as indicated by the Fear Index. During tranquil times (i.e., absence of DRN), the trading portfolio is invested 100\% in the S\&P500. The holding period of the strategies varies between one (Panel 1D) and three days (Panel 3D). The outperformance is calculated as the difference between the cumulative performance of the four trading portfolios and a long-only position in the market portfolio that is proxied by S\&P500. Assuming an initial investment of $\mathrm{U} \$ 1$, the application of the trading strategies $1 \mathrm{D}-3 \mathrm{D}$ to EW (VW, TOP, BOTTOM) yields on average between USD $0.48-2.05(0.22-0.67,0.24-0.66,0.29-2.02)$ more than a long-only market exposure. The trading period runs from January 2003 to November 2014 (3097 trading days).

\section{Concluding remarks}

Motivated by the abundance of recent behavioral finance studies showing that particular events (e.g., St. Patrick Day, Yom Kippur War, Rosh Hashanah, International Sporting Games) may have a strong effect on investors' mood, this paper tests whether DRNs have a significant positive sentiment effect among investors interested in US pharmaceutical companies and, thus, on their stock prices. This research builds on the notion that vaccine produc- 
tion for globally dangerous diseases is concentrated in a few large pharmaceutical companies. Indeed, the number of vaccine producers in the U.S. decreased dramatically from the sixties - in 1967 there were 37 vaccine producers (Masignani et al., 2003) - to just over a dozen in 2016. Rational investors design trading strategies that are based on expectations of future cash flows of these companies. We argue that rational trading should not occur because of two reasons. First, in the wake of DRNs, uncertainty surrounding distant cash flows of vaccine developers may be too high. Second, resources available for smaller pharmaceutical companies may be too limited to engage in large-scale R\&D. For instance, it is required to invest at least USD 850 million to license a new pharmaceutical product (Masignani et al., 2003). As a result, pharmaceutical stock prices should not respond to DRNs. Thus, DRNs can only lead to higher stock prices and returns of other pharmaceutical companies through altering investor sentiment about their future performance and leading to irrational trading (see also Kaplanski and Levy, 2010b). The potential negative sentiment effect induced by fear and anxiety due to DRNs is also tested, allowing us to account for two conflicting sentiment effects.

Our findings are as follows. First, we observe that DRNs exert a positive and significant effect on pharmaceutical firms' stock returns. This effect is relatively stronger for a portfolio of small stocks. We further observe that the DRN effect lasts for several days. Based on the assumption that a DRN can also generate panic, fear and anxiety among international investors, we observe that an ad hoc fear gauge index appears to exert a negative and significant effect on returns of pharmaceutical companies' stocks. Again, the effect is stronger for small relative to large stocks.

Overall, this research shows that optimism and pessimism - induced by DRNs - can significantly influence portfolio investment decisions in the pharmaceutical industry. Our findings are of utmost importance and practical usefulness for institutional and individual investors, portfolio managers, financial analysts and pharmaceutical firms. Indeed, we identify a range of exploitable investment opportunities. To this end, we design a number of trading strategies that involve a portfolio of pharmaceutical stocks and the VIX volatility index.

The results of the exercise unambiguously show that trading strategies yield positive and 
significant returns. The outcome of this exercise is also useful for portfolio managers who formulate a professional and qualified advice for investors. Financial analysts can provide a comprehensive analysis of investment opportunities in the pharmaceutical sector. Furthermore, by issuing and selling new stocks to investors, pharmaceutical firms can benefit from increasing market valuation and, hence, from lower cost fundings for R\&D spending when a global disease breaks out and accelerates. 


\section{References}

Assid, M., Gharbi, A., Dhouib, K., 2015. Joint production and subcontracting planning of unreliable multifacility multi-product production systems. Omega 50, 54-69.

Baker, M., Wurgler, J., 2006. Investor sentiment and the cross-section of stock returns. The Journal of Finance $61,1645-1680$.

Baker, M., Wurgler, J., 2007. Investor sentiment in the stock market. Journal of Economic Perspectives 21, 129-151.

Blendon, R., Benson, J. M., Des-Roches, C. M., Raleigh, E., Taylor-Clark, K., 2004. The public's response to Severe Acute Respiratory Syndrome in Toronto and the United States. Clinical Infectious Diseases 38, 925-931.

Bloom, N., 2009. The impact of uncertainty shocks. Econometrica 77, 623-685.

Boldrin, M., Levine, D. K., 2013. The case against patents. Journal of Economic Perspectives 27, 3-22.

Brown, G. W., Cliff, M. T., 2005. Investor sentiment and asset valuation. The Journal of Business 78, 405-440.

Cao, M., Wei, J., 2005. Stock market returns: A note on tempereture anomaly. Journal of Banking and Finance 29, 1559-1573.

Cen, L., Liyan-Yang, H., 2013. Investor sentiment, disagreement, and the breadth return relationship. Management Science 59, 1076-1091.

Curatola, G., Donadelli, M., Kizys, R., Riedel, M., 2016. Investor sentiment and sectoral stock returns: Evidence from World Cup games. Finance Research Letters, Forthcoming .

De Long, J., Bradford, A. S., Summers, L. H., Waldmann, R. J., 1990. Noise trader risk in financial markets. Journal of Political Economy 98, 703-738.

De Miguel, V., Garlappi, L., Uppal, R., 2009. Optimal versus naive diversification: How inefficient is the 1/N portfolio strategy? Review of Financial Studies 22, 1915-1953.

Edmans, A., García, D., Norli, Ø., 2007. Sports sentiment and stock returns. Journal of Finance 62, 19671998.

Hanna, D., Yiping, H., 2004. The impact of SARS on Asian Economies. Asian Economic Papers 3, 102-112.

Himmelmann, A., Schiereck, D., 2012. Drug approval decisions: A note on stock liquidity effects. Journal of Empirical Finance 19, 640-652.

Hinman, A., R., W. A. Orenstein, W., A., Santoli, J. M., Rodewald, L. E., Cochi, S. L., 2006. VACCINE SHORTAGES: History, impact, and prospects for the future. Annual Review of Public Health 27, 235-259.

Hirshleifer, D., Shumway, T., 2003. Good day sunshine: Stock returns and the weather. Journal of Finance $58,1009-1032$.

Horváth, B., Huizinga, H., 2015. Does the European Financial Stability Facility bail out sovereigns or banks? an event study. Journal of Money, Credit and Banking 47, 177-206.

Hou, K., Karolyi, G. A., Kho, B.-C., 2011. What factors drive global stock returns? Review of Financial Studies 24, 2527-2574. 
Huberman, G., Regev, T., 2001. Contagious speculation and a cure for cancer: A non-event that made stock prices soar. Journal of Finance 56, 387-396.

Kamstra, M. J., Kramer, L. A., Levi, M. D., 2003. Winter blues: A SAD stock market cycle. American Economic Review 93, 324-343.

Kaplanski, G., Levy, H., 2010a. Exploitable predictable irrationality: The FIFA World Cup effect on the U.S. stock market. Journal of Financial and Quantitative Analysis 45, 535-553.

Kaplanski, G., Levy, H., 2010b. Sentiment and stock prices: The case of aviation distastes. Journal of Financial Economics 95, 174-201.

Kaplanski, G., Levy, H., 2012. The holiday and Yom Kippur War sentiment effects: The Tel Aviv stock exchange (TASE). Quantitative Finance 12, 1283-1298.

Kaplanski, G., Levy, H., 2015. Do happy people make optimistic investors? Journal of Financial and Quantitative Analysis 50, 145-168.

Keogh-Brown, M. R., Smith, R. D., 2008. The economic impact of SARS: How does the reality match the predictions? Health Policy 88, 110-120.

Klibanoff, P., Lamont, O., Wizman, T., 1998. Investor reaction to salient news in closed-end country funds. Journal of Finance 53, 673-699.

Lazonick, W., Tulum, O., 2011. US biopharmaceutical finance and the sustainability of the biotech business model. Research Policy 40, 1170-1187.

Loughran, T., Schultz, P., 2004. Weather, stock returns, and the impact of localized trading behavior. Journal of Financial and Quantitative Analysis 39, 343-364.

Mairal, G., 2011. The history and the narrative of risk in the media. Health, Risk \& Society 13, 65-79.

Masignani, M., Lattanzi, M., Rappuoli, R., 2003. The value of vaccines. Vaccine 21, Supplement 2, S110 S113.

Mehra, R., Sah, R., 2002. Mood fluctuations, projection bias, and volatility of equity prices. Journal of Economic Dynamics and Control 26, 869-887.

Nofsinger, J. R., 2005. Social mood and financial economics. Journal of Behavioral Finance 6, 144-160.

Offit, P., A., 2005. Why are pharmaceutical companies gradually abandoning vaccines? Health Affairs 24, $622-630$.

Palomino, F., Renneboog, L., Zhang, C., 2009. Information salience, investor sentiment, and stock returns: The case of British soccer betting. Journal of Corporate Finance 15, 368-387.

Qiu, L., Welch, I., 2004. Investor sentiment measures. NBER Working Paper No. 10794 .

Quah, S., Hin-Peng, L., 2004. Crisis prevention and management during SARS outbreak, Singapore. Emerging Infectious Diseases 10, 364-368.

Saunders, E., 1993. Stock prices and Wall Street weather. The Journal of Finance 83, 1337-1345.

Shortridge, R. T., 2004. Market valuation of successful versus non-successfulR\&D efforts in the pharmaceutical industry. Journal of Business Finance and Accounting 31, 1301-1325. 
Smith, R. D., M. R. Keogh-Brown, M. R. a. T. B., Tait, J., 2009. The economy-wide impact of pandemic influenza on the UK: A computable general equilibrium modelling experiment. British Medical Journal pp. $1-7$.

Tetlock, P. C., 2007. Giving content to investor sentiment: The role of media in the stock market. The Journal of Finance 62, 1139-1168.

Theodossiou, A., Theodossiou, P., 2014. Stock return outliers and beta estimation: The case of U.S. pharmaceutical companies. Journal of International Financial Markets, Institutions and Money 30, 153-171.

Vasterman, P., Yzermans, J. C., Dirkzwager, A. J., 2005. The role of the media and media hypes in the aftermath of disasters. Epidemiologic Reviews 27, 107-114.

Whaley, R., 2009. Understanding the VIX. Journal of Portfolio Management 35, 98-105.

Young, M. E., King, N., Harper, S., Humphreys, K. R., 2013. The influence of popular media on perceptions of personal and population risk in possible disease outbreaks. Health, Risk \& Society 15, 103-114.

Yuan, K., Zheng, L., Zhu, Q., 2006. Are investors moonstruck? lunar phases and stock returns. Journal of Empirical Finance 13, 1-23. 


\section{APPENDIX}

\section{A Data}

\begin{tabular}{|c|c|c|c|c|c|}
\hline NO & NAME & MCAP & CAP WEIGHT & CUM SUM 1 & CUM SUM 2 \\
\hline 1 & PFIZER & 188593.1946 & 15.5172 & 15.5172 & 100.0000 \\
\hline 2 & JOHNSON \& JOHNSON & 180892.8180 & 14.8836 & 30.4008 & 84.4828 \\
\hline 3 & GLAXOSMITHKLINE & 124710.2614 & 10.2610 & 40.6617 & 69.5992 \\
\hline 4 & MERCK \& COMPANY & 114423.0361 & 9.4146 & 50.0763 & 59.3383 \\
\hline 5 & ABBOTT LABORATORIES & 73520.9544 & 6.0492 & 56.1255 & 49.9237 \\
\hline 6 & ASTRAZENECA & 71562.0971 & 5.8880 & 62.0135 & 43.8745 \\
\hline 7 & AMGEN & 68315.0835 & 5.6209 & 67.6344 & 37.9865 \\
\hline 8 & ELI LILLY & 62379.5576 & 5.1325 & 72.7669 & 32.3656 \\
\hline 9 & BRISTOL MYERS SQUIBB & 61626.7479 & 5.0706 & 77.8374 & 27.2331 \\
\hline 10 & GILEAD SCIENCES & 35021.1338 & 2.8815 & 80.7189 & 22.1626 \\
\hline 11 & NOVO NORDISK & 34284.6745 & 2.8209 & 83.5398 & 19.2811 \\
\hline 12 & TEVA PHARM.INDS & 28821.6231 & 2.3714 & 85.9112 & 16.4602 \\
\hline 13 & BIOGEN IDEC & 20895.2112 & 1.7192 & 87.6304 & 14.0888 \\
\hline 14 & ALLERGAN & 17904.0011 & 1.4731 & 89.1035 & 12.3696 \\
\hline 15 & GENZYME & 14939.5048 & 1.2292 & 90.3327 & 10.8965 \\
\hline 16 & FOREST LABS & 13182.6281 & 1.0846 & 91.4174 & 9.6673 \\
\hline 17 & VALEANT & 9007.8462 & 0.7412 & 92.1585 & 8.5826 \\
\hline 18 & ACTAVIS & 7885.8495 & 0.6488 & 92.8074 & 7.8415 \\
\hline 19 & ELAN & 7077.8720 & 0.5824 & 93.3897 & 7.1926 \\
\hline 20 & MYLAN & 6572.2429 & 0.5408 & 93.9305 & 6.6103 \\
\hline 21 & ALEXION PHARMS & 6338.2386 & 0.5215 & 94.4520 & 6.0695 \\
\hline 22 & SIGMA ALDRICH & 5935.0372 & 0.4883 & 94.9403 & 5.5480 \\
\hline 23 & VERTEX PHARMS & 5909.6323 & 0.4862 & 95.4265 & 5.0597 \\
\hline 24 & REGENERON PHARMS & 5319.3428 & 0.4377 & 95.8642 & 4.5735 \\
\hline 25 & PERRIGO & 4580.8478 & 0.3769 & 96.2411 & 4.1358 \\
\hline 26 & CEPHALON & 4198.4394 & 0.3454 & 96.5866 & 3.7589 \\
\hline 27 & AMYLIN PHARMS & 2882.0073 & 0.2371 & 96.8237 & 3.4134 \\
\hline 28 & IDEXX LABORATORIES & 2858.6592 & 0.2352 & 97.0589 & 3.1763 \\
\hline 29 & OSI PHARMS. & 2295.2012 & 0.1888 & 97.2477 & 2.9411 \\
\hline 30 & ONYX PHARMS. & 2212.3014 & 0.1820 & 97.4298 & 2.7523 \\
\hline 31 & NBTY DEAD & 2154.6428 & 0.1773 & 97.6070 & 2.5702 \\
\hline 32 & BIO-TECHNE & 2134.9189 & 0.1757 & 97.7827 & 2.3930 \\
\hline 33 & PDL BIOPHARMA & 1658.8950 & 0.1365 & 97.9192 & 2.2173 \\
\hline 34 & CUBIST PHARMACEUTICALS & 1521.3011 & 0.1252 & 98.0444 & 2.0808 \\
\hline 35 & PHARMACYCLICS & 1377.5567 & 0.1133 & 98.1577 & 1.9556 \\
\hline 36 & IMMUCOR DEAD & 1200.8945 & 0.0988 & 98.2565 & 1.8423 \\
\hline 37 & ISIS PHARMACEUTICALS & 1113.6985 & 0.0916 & 98.3482 & 1.7435 \\
\hline 38 & PAR PHARMACEUTICAL COS. & 1078.8536 & 0.0888 & 98.4369 & 1.6518 \\
\hline 39 & NEKTAR THERAPEUTICS & 1074.3753 & 0.0884 & 98.5253 & 1.5631 \\
\hline 40 & CHATTEM DEAD & 1023.8235 & 0.0842 & 98.6096 & 1.4747 \\
\hline 41 & VIROPHARMA DEAD & 945.5819 & 0.0778 & 98.6874 & 1.3904 \\
\hline 42 & MARTEK BIOSCIENCES DEAD & 906.6911 & 0.0746 & 98.7620 & 1.3126 \\
\hline 43 & QUESTCOR PHARMS. & 857.4462 & 0.0705 & 98.8325 & 1.2380 \\
\hline 44 & QLT (NAS) & 850.3269 & 0.0700 & 98.9025 & 1.1675 \\
\hline 45 & NPS PHARMACEUTICALS & 793.5564 & 0.0653 & 98.9678 & 1.0975 \\
\hline 46 & ENZON PHARMS. & 699.0431 & 0.0575 & 99.0253 & 1.0322 \\
\hline 47 & MERIDIAN BIOSCIENCE & 583.7499 & 0.0480 & 99.0733 & 0.9747 \\
\hline 48 & USANA HEALTH SCIENCES & 524.6496 & 0.0432 & 99.1165 & 0.9267 \\
\hline 49 & IMMUNOGEN & 523.7035 & 0.0431 & 99.1596 & 0.8835 \\
\hline 50 & CAMBREX & 518.7217 & 0.0427 & 99.2022 & 0.8404 \\
\hline 51 & VIVUS & 485.4240 & 0.0399 & 99.2422 & 0.7978 \\
\hline 52 & NEOGEN & 472.8012 & 0.0389 & 99.2811 & 0.7578 \\
\hline 53 & QUIDEL & 396.0453 & 0.0326 & 99.3137 & 0.7189 \\
\hline 54 & GERON & 392.1340 & 0.0323 & 99.3459 & 0.6863 \\
\hline 55 & CTI BIOPHARMA & 354.9887 & 0.0292 & 99.3751 & 0.6541 \\
\hline 56 & AMAG PHARMACEUTICALS & 354.7572 & 0.0292 & 99.4043 & 0.6249 \\
\hline 57 & AMARIN & 353.9426 & 0.0291 & 99.4335 & 0.5957 \\
\hline 58 & CELLDEX THERAPEUTICS & 339.2544 & 0.0279 & 99.4614 & 0.5665 \\
\hline 59 & ASTEX PHARMACEUTICALS & 328.9040 & 0.0271 & 99.4884 & 0.5386 \\
\hline
\end{tabular}




\begin{tabular}{|c|c|c|c|c|c|}
\hline 60 & ORASURE TECHS. & 323.2983 & 0.0266 & 99.5150 & 0.5116 \\
\hline 61 & XOMA & 312.4535 & 0.0257 & 99.5407 & 0.4850 \\
\hline 62 & PROGENICS PHARMS. & 311.1469 & 0.0256 & 99.5663 & 0.4593 \\
\hline 63 & SAREPTA THERAPEUTICS & 270.2514 & 0.0222 & 99.5886 & 0.4337 \\
\hline 64 & CERUS & 269.7842 & 0.0222 & 99.6108 & 0.4114 \\
\hline 65 & NOVAVAX & 261.0639 & 0.0215 & 99.6323 & 0.3892 \\
\hline 66 & FLAMEL TECHS. & 252.9481 & 0.0208 & 99.6531 & 0.3677 \\
\hline 67 & HI-TECH PHML. & 230.6911 & 0.0190 & 99.6720 & 0.3469 \\
\hline 68 & BIOCRYST PHARMS. & 227.5715 & 0.0187 & 99.6908 & 0.3280 \\
\hline 69 & DEPOMED & 218.5011 & 0.0180 & 99.7087 & 0.3092 \\
\hline 70 & ARQULE & 211.1096 & 0.0174 & 99.7261 & 0.2913 \\
\hline 71 & SCICLONE PHARMS. & 192.3768 & 0.0158 & 99.7419 & 0.2739 \\
\hline 72 & VICAL & 191.0992 & 0.0157 & 99.7577 & 0.2581 \\
\hline 73 & PEREGRINE PHARMS. & 191.0939 & 0.0157 & 99.7734 & 0.2423 \\
\hline 74 & ARCA BIOPHARMA & 177.9806 & 0.0146 & 99.7880 & 0.2266 \\
\hline 75 & ONCOTHYREON (NAS) & 163.0754 & 0.0134 & 99.8015 & 0.2120 \\
\hline 76 & TRINITY BIOTECH & 161.7711 & 0.0133 & 99.8148 & 0.1985 \\
\hline 77 & DISCOVERY LABORATORIES & 160.3241 & 0.0132 & 99.8280 & 0.1852 \\
\hline 78 & REPLIGEN & 156.1896 & 0.0129 & 99.8408 & 0.1720 \\
\hline 79 & ANIKA THERAPEUTICS & 131.3024 & 0.0108 & 99.8516 & 0.1592 \\
\hline 80 & SIGA TECHNOLOGIES & 130.3700 & 0.0107 & 99.8623 & 0.1484 \\
\hline 81 & DUSA PHARMACEUTICALS & 124.5980 & 0.0103 & 99.8726 & 0.1377 \\
\hline 82 & CASI PHARMACEUTICALS & 121.1209 & 0.0100 & 99.8826 & 0.1274 \\
\hline 83 & THERAGENICS & 117.7449 & 0.0097 & 99.8922 & 0.1174 \\
\hline 84 & REPROS THERAPEUTICS & 101.2414 & 0.0083 & 99.9006 & 0.1078 \\
\hline 85 & LA JOLLA PHARM. & 100.3018 & 0.0083 & 99.9088 & 0.0994 \\
\hline 86 & ONCOGENEX PHARMS. & 99.5011 & 0.0082 & 99.9170 & 0.0912 \\
\hline 87 & HEMISPHERX BIOPHARMA & 99.2742 & 0.0082 & 99.9252 & 0.0830 \\
\hline 88 & GTC BIOTH. & 96.8866 & 0.0080 & 99.9332 & 0.0748 \\
\hline 89 & PONIARD PHARMS. & 90.9323 & 0.0075 & 99.9406 & 0.0668 \\
\hline 90 & CYTRX & 84.8427 & 0.0070 & 99.9476 & 0.0594 \\
\hline 91 & AASTROM BIOSCIENCES & 84.6644 & 0.0070 & 99.9546 & 0.0524 \\
\hline 92 & HARBOR DIVERSIFIED & 74.8975 & 0.0062 & 99.9607 & 0.0454 \\
\hline 93 & AMPLIPHI BIOSCIENCES & 74.3217 & 0.0061 & 99.9669 & 0.0393 \\
\hline 94 & PALATIN TECHS. & 66.2649 & 0.0055 & 99.9723 & 0.0331 \\
\hline 95 & OXIGENE & 64.4941 & 0.0053 & 99.9776 & 0.0277 \\
\hline 96 & HESKA & 56.3439 & 0.0046 & 99.9823 & 0.0224 \\
\hline 97 & UNITED GUARDIAN & 54.0690 & 0.0044 & 99.9867 & 0.0177 \\
\hline 98 & PROPHASE LABS & 52.6426 & 0.0043 & 99.9910 & 0.0133 \\
\hline 99 & IGI LABORATORIES & 39.7254 & 0.0033 & 99.9943 & 0.0090 \\
\hline 100 & NATURAL ALTS.INTL. & 39.0276 & 0.0032 & 99.9975 & 0.0057 \\
\hline 101 & CYANOTECH & 19.0884 & 0.0016 & 99.9991 & 0.0025 \\
\hline 102 & IMMUCELL & 11.1632 & 0.0009 & 100.0000 & 0.0009 \\
\hline
\end{tabular}

Table A.1: Pharmaceutical Companies

Note: In this table, pharmaceutical companies are sorted on market capitalization (in millions of USD) (column MCAP). Market capitalization shares for each company are reported in column CAP WEIGHT. Columns CUM SUM 1 accumulates capitalization. The last column shows capitalization shares in reverse order, i.e., the overall capitalization attributed to the remaining firms, once the largest firms are accounted for. 


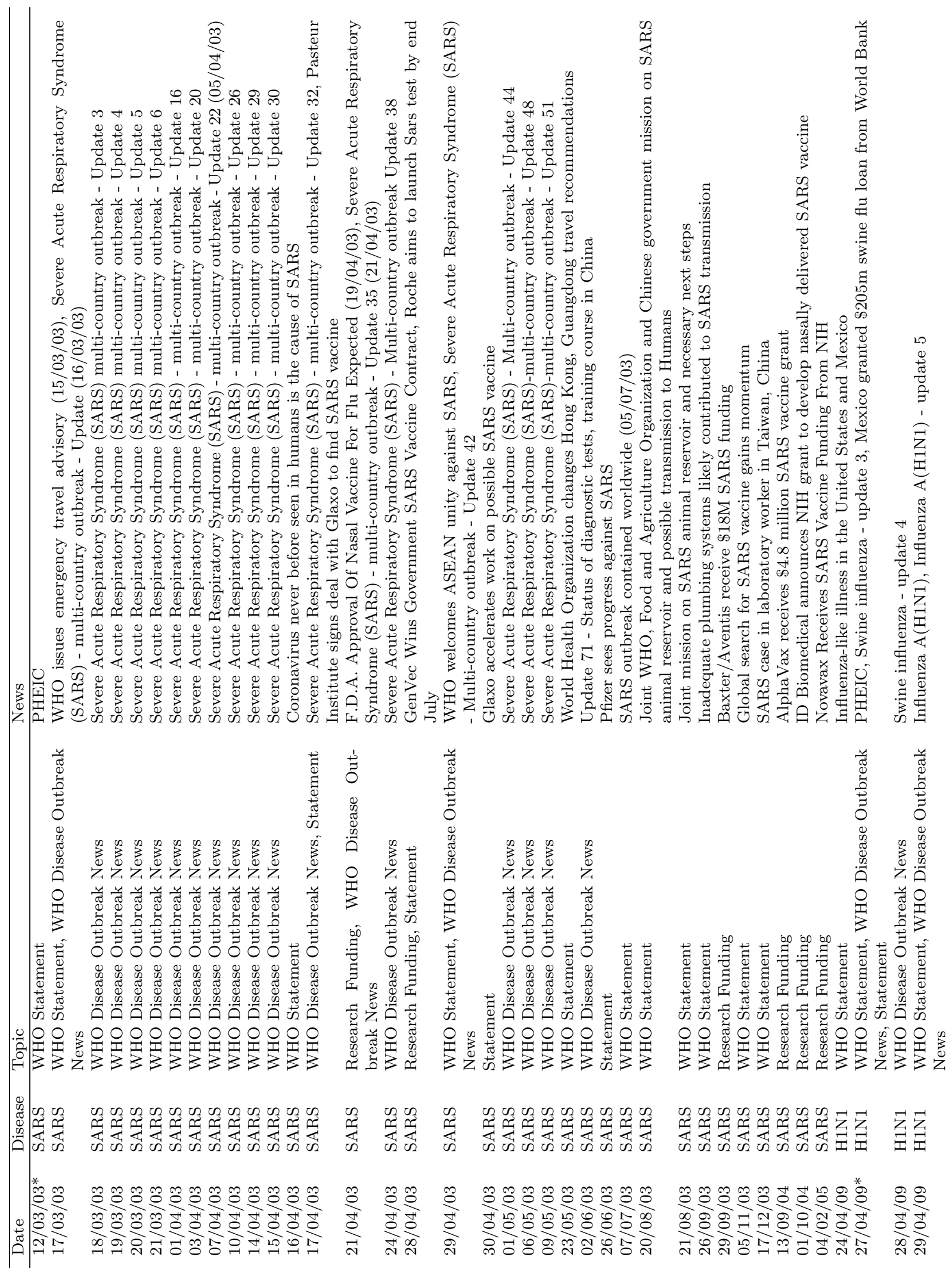



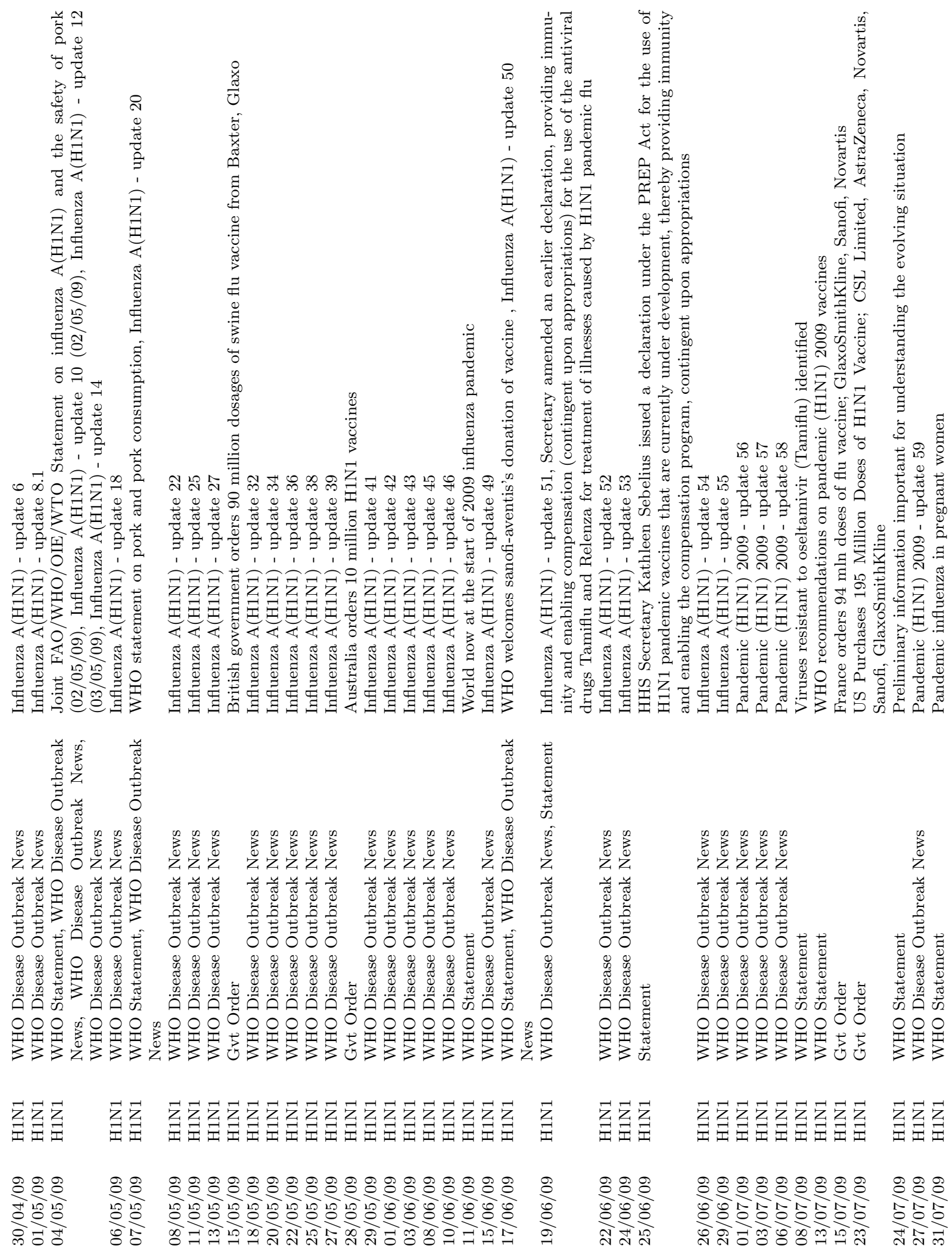

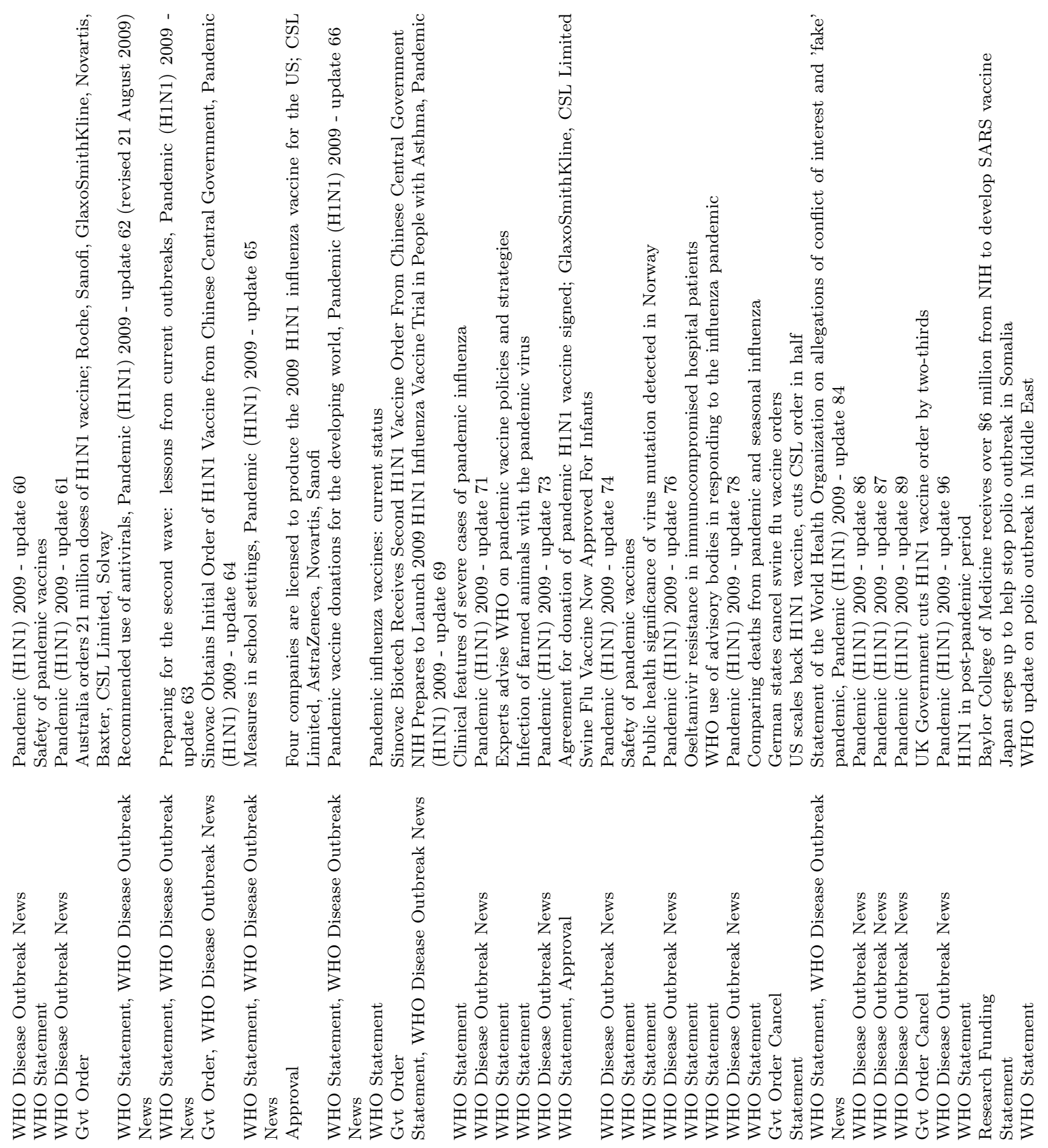

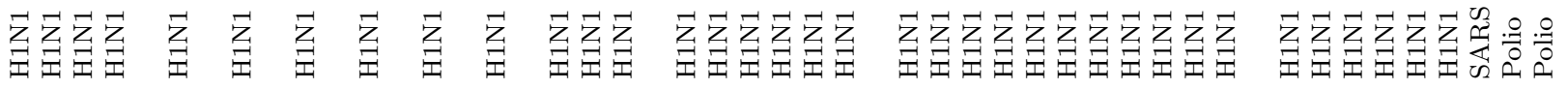

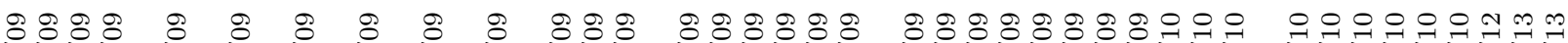
कo

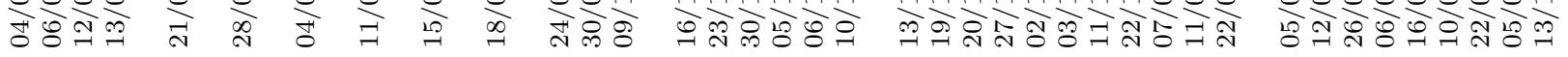




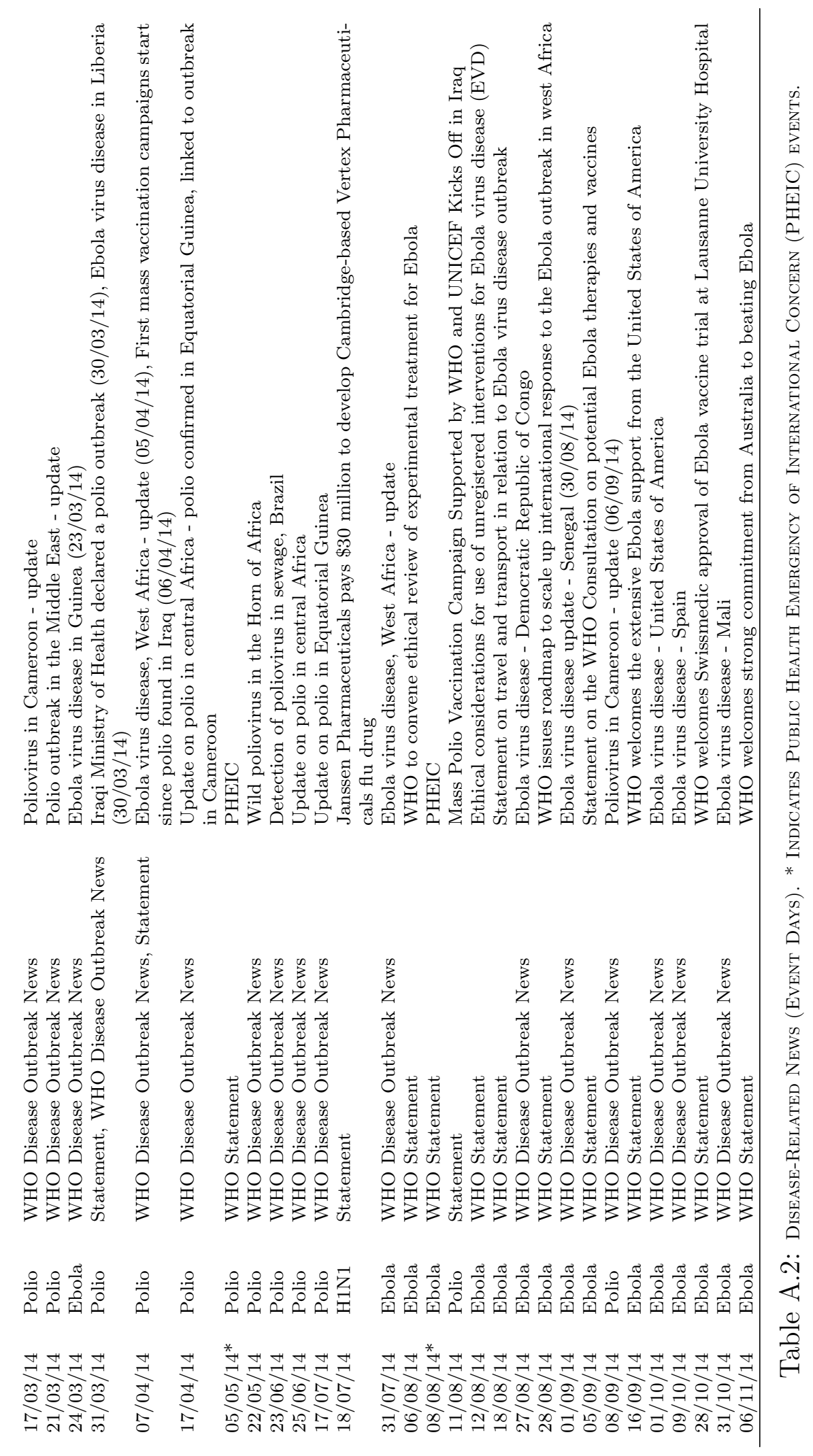




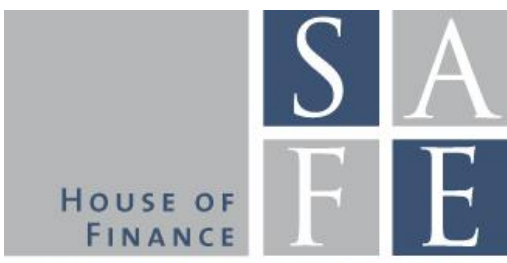

WORKING PAPER SERIES

\section{Recent Issues}

No. 157 Steffen Meyer, Linda Urban, Sophie Ahlswede

No. 156 Reint Gropp, Thomas Mosk, Steven Ongena, Carlo Wix

No. $155 \quad$ Vahid Saadi

No. 154 Brigitte Haar

No. 153 Julia Hirsch, Uwe Walz

No. 152 Viral Acharya, Tim Eisert, Christian Eufinger, Christian Hirsch

No. 151 Michael Schneider, Fabrizio Lillo, Loriana Pelizzon

No. 150 Vanya Horneff, Raimond Maurer, Olivia S. Mitchell

No. 149 Massimiliano Caporin, Aleksey Kolokolov, Roberto Renò

No. 148 Sven-Thorsten Jakusch

No. 147 Andreas Hackethal, Sven-Thorsten Jakusch, Steffen Meyer

No. 146 Sven-Thorsten Jakusch, Steffen Meyer, Andreas Hackethal
Does feedback on personal investment success help?

Bank Response To Higher Capital

Requirements: Evidence From A QuasiNatural Experiment

Mortgage Supply and the US Housing Boom: The Role of the Community Reinvestment Act

Shareholder Wealth vs. Stakeholder interests? Evidence from Code Compliance under the German Corporate Governance Code

The Financing Dynamics of Newly Founded Firms

Whatever it Takes: The Real Effects of Unconventional Monetary Policy

How Has Sovereign Bond Markets Liquidity Changed? - An Illiquidity Spillover Analysis

Putting the Pension back in 401(k) Plans: Optimal versus Default Longevity Income Annuities

Systemic Co-Jumps

On the Applicability of Maximum Likelihood Methods: From Experimental to Financial Data

Taring all Investors with the same Brush? Evidence for Heterogeneity in Individual Preferences from a Maximum Likelihood Approach

Taming Models of Prospect Theory in the Wild? Estimation of Vlcek and Hens (2011) 